UNIVERSIDADE DE BRASÍLIA

FACULDADE DE CIÊNCIAS DA SAÚDE

PROGRAMA DE PÓS-GRADUÇÃO EM BIOÉTICA

TATIANE TEIXEIRA VAZ DE OLIVEIRA

\title{
ANÁLISE BIOÉTICA SOBRE O DUPLO PADRÃO EM VACINAS PEDIÁTRICAS
}

Dissertação apresentada como requisito parcial para a obtenção do título de Mestre em Bioética pelo Programa de Pós-Graduação em Bioética da Universidade de Brasília.

Orientador: Dr. José Garrofe Dórea

Linha de Pesquisa: Situações Persistentes em Bioética e Saúde Pública

BRASÍLIA - DF 2017 


\section{FICHA CATALOGRÁFICA}

OLIVEIRA, TATIANE TEIXEIRA VAZ

Análise Bioética sobre o Duplo Padrão em Vacinas Pediátricas.

Orientador: José Garrofe Dórea

Dissertação de Mestrado - Universidade de Brasília/Programa de Pós-

Graduação em Bioética, 2017.

1. Bioética de Intervenção. 2. Duplo padrão. 3. Vacinas. 4. Timerosal 


\section{ANÁLISE BIOÉTICA SOBRE O DUPLO PADRÃO EM VACINAS PEDIÁTRICAS}

Dissertação apresentada como requisito parcial para a obtenção do título de Mestre em Bioética pelo Programa de Pós-Graduação em Bioética da Universidade de Brasília.

Aprovado em: 10 de fevereiro de 2017.

\section{BANCA EXAMINADORA}

Prof. Dr. José Garrofe Dórea (Presidente)

Universidade de Brasília

Prof. Dr. Volnei Garrafa

Universidade de Brasília

Prof. Dr. Leandro Brambilla Martorell

Universidade Federal de Goiás

Prof. Dr. Wanderson Flor do Nascimento (Suplente)

Universidade de Brasília 
Dedico este trabalho ao meu marido Antônio Caetano e meu filho Lucas Caetano, pela paciência, companheirismo e empenho para que este sonho se concretizasse. 


\section{AGRADECIMENTOS}

A Deus pelos desafios inerentes a esta jornada, que me tornaram mais forte e convicta dos meus ideais.

Aos meus pais José de Arimateia e Maria Lúcia, pela dedicação e encorajamento; e meus irmãos Taciane e João Paulo, pelo carinho e amizade.

Ao meu orientador, Dr. José Garrofe Dórea, grande pesquisador e referência mundial sobre o mercúrio. Sempre disponível e solícito ao transmitir seus conhecimentos de forma paciente e acolhedora.

Ao Prof. Dr. Volnei Garrafa, pela imensa generosidade ao longo de todo o curso e especialmente nos momentos finais desta dissertação. Obrigada por compartilhar tamanha riqueza de conhecimentos, sobretudo, a Bioética de Intervenção, teoria socialmente comprometida e transformadora.

Aos amigos de curso, em especial a Luziana Maranhão, Raylla Albuquerque, lane Almeida, Talita Cavalcante e Roberta Ataídes.

Ao Prof. Dr. Jovanny Medeiros, médico neurologista e docente do curso de Fisioterapia, na Universidade Estadual da Paraíba e meu orientador na Graduação. Agradeço por ter sido um referencial para minha vida acadêmica.

À Linete Oliveira, minha cunhada, pela acolhida em sua casa sempre que precisamos ir a Brasília, depois da nossa mudança para o Piauí.

À CAPES pela bolsa concedida, que foi de extrema importância para a realização do mestrado. 


\section{RESUMO}

O objeto deste estudo verificou a similaridade entre o duplo padrão de segurança em vacinas pediátricas, que acontece através da utilização de vacinas conservadas em mercúrio, administradas a gestantes, prematuros e recém-nascidos nos países periféricos e o duplo padrão em pesquisas, chancelado pelas alterações recentes na Declaração de Helsinki. Tais alterações ocorreram com o objetivo de garantir interesses econômicos e dizem respeito ao uso de placebo e enfraquecimento das obrigações dos patrocinadores com os sujeitos de pesquisa ao término dos ensaios clínicos. A discussão será realizada a partir da Bioética de Intervenção, que é uma teoria socialmente comprometida e desenvolvida na Cátedra Unesco de Bioética, e direciona atenção especial para as questões relativas aos problemas éticos persistentes dos países periféricos, sobretudo, através da politização de conflitos morais. Crítica às formas de imperialismos morais, impostos, especialmente, por países centrais aos periféricos, possui desde a sua gênese, intrínseca relação com as questões de saúde pública. A Declaração Universal sobre Bioética e Direitos Humanos representou um marco para o avanço nas discussões referentes à saúde pública e inclusão social, com a incorporação de princípios como Benefício e Dano (art. 4), Respeito pela Vulnerabilidade Humana e Integridade Individual (art. 8), Igualdade, Justiça e Equidade (art. 10), que foram utilizados como fundamento na discussão sobre o duplo padrão em vacinas pediátricas. Países centrais eliminaram o uso do timerosal em vacinas infantis há mais de uma década, em observância ao Princípio da Precaução. Entretanto, a Organização Mundial de Saúde advoga pela continuidade do uso de vacinas conservadas em mercúrio, influenciando países periféricos a manterem sua utilização. Foram analisados criticamente dois documentos norteadores para a eliminação e/ou manutenção do timerosal como conservante de vacinas infantis: Joint Statment of the American Academy of Pediatrics and The United States Public Health e The Safety of Thiomersal, da OMS. Constatou-se que os quatro "Pês", utilizados pela Bioética de Intervenção: prevenção, proteção, precaução e prudência, podem ser invocados para a observância dos padrões éticos no manejo do processo de vacinação infantil, fornecendo sustentabilidade às ações a serem executadas pela Agência Nacional de Vigilância Sanitária, com vistas à minimização de danos e riscos.

Palavras-chave: Bioética de Intervenção; duplo padrão; vacinas; timerosal. 


\begin{abstract}
The object of this study shows the similarity between the double standard on pediatric vaccine safety, which happens through the use of vaccines stored in mercury and given to fetuses, premature infants and newborns in peripheral countries and the double standard on researches, the latter supported by the recent changes in the Declaration of Helsinki. Such changes have occurred to secure economic interests, and are related to the use of placebo and relaxation of the sponsors' liabilities on trial subjects upon the completion of clinical trials. The discussion will be based on the Intervention Bioethics, that is a theory socially committed developed at the Brasília University's Unesco Chair in Bioethics, which directs special attention to issues related to the persistent ethical problems of the peripheral countries, particularly, through politicization of moral conflicts. Criticism to moral imperialism forms, imposed mainly by central on peripheral countries, it has had since its genesis, an intrinsic relation to public health issues. In the same way, the Universal Declaration on Bioethics and Human Rights represented a landmark for the progress of discussions concerning public health and social inclusion, by incorporating principles such as the Benefit and Harm (art. 4), Respect for Human Vulnerability and Personal Integrity (art. 8), Equality, Justice and Equity (art. 10), which will also serve as a basis for discussion about the double standard on pediatric vaccine safety. Central countries like the United States eliminated the use of Thimerosal in childhood vaccines more than a decade ago, complying with the Precautionary Principle. However, the World Health Organization advocates for continuing the use of vaccines stored in mercury, influencing peripheral countries to keep its use. Two guidance documents for the elimination and/or maintenance of Thimerosal as the preservative for childhood vaccine have been critically assessed: Joint Statment of the American Academy of Pediatrics and The United States Public Health (1999); and The Safety of Thiomersal (2012). It has been noted that the four "Pês", developed by the Intervention Bioethics: prevention, protection, precaution and prudence, can be invoked for the compliance of ethical standards in the handling of the childhood vaccination process, providing sustainability to actions to be conducted by the Brazilian Health Surveillance Agency, aiming to minimize risks and harms to the child population.
\end{abstract}

Key-words: Intervention Bioethics; double standard; vaccine, thimerosal. 


\section{LISTA DE QUADROS}

Quadro 1 - Vacinas que contém Timerosal recomendadas pelo Programa Nacional de Imunização do Brasil às crianças de 0 a 6 meses de vida, doses e características.

Quadro 2 - Vacinas que contém Timerosal recomendadas pelo Programa Nacional de Imunização do Brasil a gestantes, doses e características. 


\section{LISTA DE ABREVIATURAS E SIGLAS}

\begin{tabular}{ll} 
AAP & American Academy of Pediatrics \\
ANVISA & Agência Nacional de Vigilância Sanitária \\
ATSDR & Agency for Toxic Substances and Disease Registry \\
BCG & Bacilo de Calmette \& Guérin \\
B \& C & Beauchamp e Childress \\
BI & Bioética de Intervenção \\
CDC & Center for Disease Control and Prevention \\
CFR & Code of Federal Regulations \\
COMEST & World Commission on the Ethics of Scientific Knowledge and \\
& Technology \\
CRIE & Centros de Referência de Imunobiológicos Especiais \\
DF & Distrito Federal \\
DUDBH & Declaração Universal sobre Bioética e Direitos Humanos \\
Dt & Dupla adulto \\
EUA & Estados Unidos da América \\
EtHg & Etilmercúrio \\
EPA & Environmental Protection Agency \\
FA & Febre amarela \\
FAO & Organização das Nações Unidas para Agricultura e Alimentação \\
FDA & Food and Drug Administration \\
GSK & Glaxo Smith Kline \\
GAVI & Global Alliance for Vaccines and Immunization \\
HBSAG & Antígeno de superfície do vírus da hepatite B \\
Hg & Mercúrio \\
HRSA & Health Resources and Services Administration \\
IAB & International Association of Bioethics \\
MeHg & Metilmercúrio \\
\hline
\end{tabular}




$\begin{array}{ll}\text { NIH } & \text { National Institutes of Health } \\ \text { NVGH } & \text { Novartis Vaccines for Global Health } \\ \text { OMS } & \text { Organização Mundial de Saúde } \\ \text { PNI } & \text { Programa Nacional de Imunizações } \\ \text { PP } & \text { Princípio da precaução } \\ \text { SNC } & \text { Sistema nervoso central } \\ \text { SBIm } & \text { Sociedade Brasileira de Imunizações } \\ \text { SBP } & \text { Sociedade Brasileira de Pediatria } \\ \text { SUS } & \text { Sistema Único de Saúde } \\ \text { UNESCO } & \text { Organização das Nações Unidas para a Educação, a Ciência e } \\ & \text { a Cultura } \\ \text { UnB } & \text { Universidade de Brasília } \\ \text { UNEP } & \text { United Nations Environment Programme } \\ \text { UNICEF } & \text { Fundo das Nações Unidas para a Infância } \\ \text { VCT } & \text { Vacinas contendo timerosal } \\ \text { WMA } & \text { World Medical Association }\end{array}$




\section{SUMÁRIO}

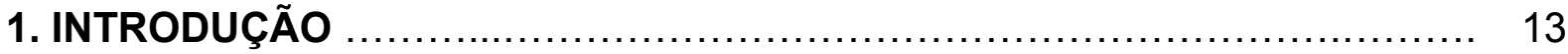

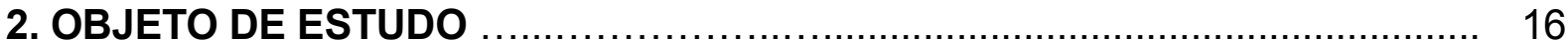

2.1 Contextualizando a Problemática: A Convenção de Minamata ................... 16

2.2 Organomercuriais: Metilmercúrio e Etilmercúrio ............................... 17

2.3 Timerosal e o Duplo Padrão de Segurança Adotado para Vacinas Pediátricas.. 19

2.4 Timerosal e Vacinas em Frascos Multidoses ................................... 21

3. FUNDAMENTAÇÃO TEÓRICA - A BIOÉTICA ................................ 23

3.1 Breve Histórico …............................................................... 23

3.2 Bioética de Intervenção .................................................... 25

3.3. Prevenção de Danos e o Princípio da Precaução .................................. 26

3.4. Imperialismo Moral no Duplo Padrão de Vacinas ................................ 29

3.4.1 Considerações Gerais.................................................................. 29

3.4.2 Imperialismo Moral e o Mercado de Vacinas .............................. 30

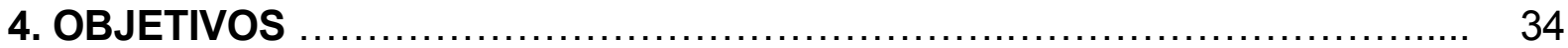

4.1 Objetivo Geral ................................................................. 34

4.2 Objetivos Específicos ….......................................................... 34

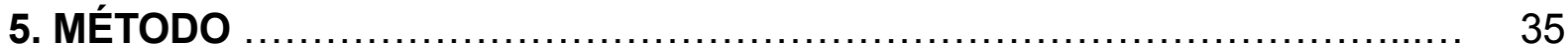

6. RESULTADOS E ANÁLISE ….................................................. 36

6.1 Vacinas contendo timerosal administradas desde o nascimento até os seis primeiros meses de vida e durante o período gestacional ................................. 36

6.2 Análise do documento Joint Statement of the American Academy of Pediatrics and the United States Public Health, 1999 ..................................................... 38

6.2.1 Situação específica de recém-nascidos prematuros e de baixo peso...... 38 6.3 Análise descritiva do documento The Safety of Thimerosal, 2012 ................. 41 
7.1 O Mercado de Vacinas ............................................................................ 44

7.2 Os Quatro "PÊS" da Bioética de Intervenção ............................................... 46

7.3 Declaração Universal Sobre Bioética e Direitos Humanos .............................. 48

7.3.1 Benefício e Dano ......................................................................... 49

7.3.2 Respeito pela Vulnerabilidade Humana e Integridade Individual ........... $\quad 51$

7.3.3 Igualdade, Justiça e Equidade ........................................................ 54

7.4 Mudança de Paradigma: Parto Domiciliar e Postergação da Vacina Hepatite B ....... 58

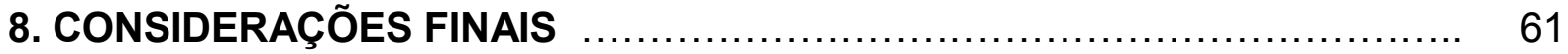

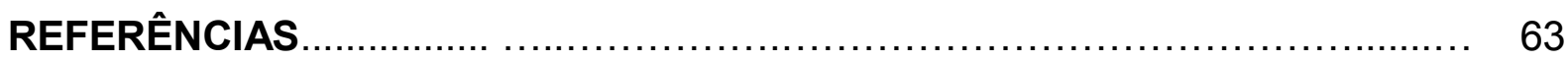

Anexos 


\section{INTRODUÇÃO}

As vacinas possuem reconhecido custo-efetividade, atuando na prevenção, controle, eliminação e erradicação das doenças imunopreveníveis, bem como na redução de morbimortalidades (1). Entretanto, apesar de ser uma das maiores conquistas para a saúde pública, o processo de imunização não é totalmente isento de riscos (2), especialmente no que concerne às vacinas em frascos multidoses conservadas em mercúrio, utilizadas para a imunização de crianças nos países periféricos.

Sabe-se que o mercúrio $(\mathrm{Hg})$ é um dos elementos mais tóxicos encontrados na tabela periódica (3) e está presente no dia a dia das populações sob variadas formas, desde a contaminação de alimentos como peixe e arroz (4)(5); na composição de cosméticos e produtos de beleza, obturações dentárias, aparelhos para aferição de pressão arterial e termômetros (6). Destaca-se o uso do mercúrio em vacinas multidoses administradas na infância em países periféricos como Brasil e Chile, através da utilização do Timerosal (7), que é o nome comercial utilizado para o composto organomercurial que se decompõe em etilmercúrio (etHg) e tiosalicilato, correspondendo a $49,55 \%$ de $\mathrm{Hg}(8)$.

As crianças de países periféricos representam o grupo mais suscetível aos efeitos danosos de substâncias tóxicas (9), sendo o intervalo entre o nascimento e os seis primeiros meses de vida o período mais crítico de exposição pós-natal a substâncias potencialmente danosas ao sistema nervoso central (SNC) (10). Nos países centrais, lactentes são expostos, via de regra, a apenas uma forma de mercúrio orgânico, o metilmercúrio (meHg). Contudo, nos países periféricos, além da exposição ao meHg por meio da ingestão de alimentos contaminados, vacinas contendo Timerosal (VCT) expõem a população infantil ao etilmercúrio (11). Situações como desnutrição e coexposição a variados agentes tóxicos são agravantes para esta população, sobretudo, durante o período intrauterino $(12,4)$.

Embora o Timerosal tenha sido utilizado por muito tempo em medicamentos e fungicidas, não existem informações acuradas a respeito da margem de segurança 
para seu uso em seres humanos, especialmente em fetos, recém-nascidos e crianças (13). Por isso, aplicando o Princípio da Precaução (PP) (14), o Serviço de Saúde Pública dos Estados Unidos da América (EUA), incluindo o National Institutes of Health (NIH), o Center for Disease Control and Prevention (CDC), o Health Resources and Services Administration (HRSA) e a American Academy of Pediatrics (AAP) emitiram duas declarações conjuntas, em 1999 e 2000, orientando para que a eliminação e/ou redução do Timerosal como conservante de vacinas fosse realizada o mais rápido possível $(15,16)$. A Organização Mundial de Saúde (OMS), entretanto, emitiu em 2012 um parecer favorável à continuidade do uso de VCT (17), o que legitima o uso de tais vacinas em crianças em países periféricos.

Assim, foi realizada uma análise crítica a respeito do uso indiscriminado de conservante potencialmente neurotóxico em vacinas pediátricas nos países periféricos, através de uma abordagem sobre como as formas de imperialismos moral e ético se manifestam no tocante ao duplo padrão de vacinação. Essa discussão foge à abordagem da Bioética Principialista, ancorada no princípio da autonomia, que apresenta limitações para explicar as demandas persistentes dos países periféricos (18), pois questões dessa ordem ultrapassam a análise meramente biomédica ou biotecnológica, envolvendo aspectos econômicos, sociais e sanitários estruturais dos países periféricos (19). Alcança a vulnerabilidade de populações que desconhecem os riscos a que estão sendo expostas e foge ao controle individual, uma vez que o programa de vacinação é compulsório no Brasil (20).

Nesse sentido, o duplo padrão de segurança em vacinas infantis será analisado a partir de uma visão periférica originada na América Latina, a Bioética de Intervenção (BI) (21). Nascimento e Garrafa (2011) reconhecem a Bioética de Intervenção como uma "ferramenta de denúncia, reflexão e busca de alternativas para a solução de problemas (bio)éticos que aparecem em um contexto típico de desigualdades registradas no hemisfério sul" (22, p. 288). Questionamos, portanto, se é moralmente aceitável que crianças de países periféricos sejam submetidas ao mercúrio em vacinas, substância potencialmente neurotóxica, enquanto crianças de países centrais são poupadas de tal exposição, observando-se o Princípio da Precaução.

Este tema é objeto de estudo da linha de pesquisa Situações Persistentes, desenvolvida na Cátedra Unesco de Bioética da Universidade de Brasília (UNB) e 
remete às condições de injustiças que se perpetuam ao longo do tempo, tais como exclusão social, pobreza, variadas formas de discriminação, bem como escassez de recursos para a saúde. $(21,23$.) O objetivo geral é promover uma análise bioética a respeito da exposição intencional ao mercúrio em vacinas, agravando desnecessariamente a exposição de gestantes (fetos), prematuros e recém-nascidos a neurotóxicos nos países periféricos. Embora a eliminação do componente tenha sido realizada nas vacinas dos países centrais, os países periféricos continuam utilizando o Timerosal de forma corriqueira.

Nesse sentido, a Declaração Universal sobre Bioética e Direitos Humanos (DUBDH), homologada em 19 de outubro de 2005 pela Organização das Nações Unidas para a Educação, a Ciência e a Cultura (UNESCO) (24) representa um marco fundamental para a ampliação da Epistemologia da Bioética para além do caráter biomédico-biotecnológico do Principialismo de Beauchamp e Childress. Apesar de ser um documento normativo não vinculante, a DUBDH é capaz de influenciar a criação de leis nos diversos países, e abrange princípios importantes para a análise e discussão sobre o duplo padrão de vacinas infantis, a saber: Benefício e dano (art. 4); Respeito pela Vulnerabilidade Humana e pela Integridade Individual (art. 8); Igualdade, Justiça e Equidade (art. 10) (25). 


\section{MARCO REFERENCIAL - O OBJETO DE ESTUDO}

\subsection{CONTEXTUALIZANDO A PROBLEMÁTICA: A CONVENÇÃO DE MINAMATA}

Acontecimentos trágicos foram decisivos para que o grau de nocividade do mercúrio fosse considerado, a exemplo da contaminação das águas da Baía de Minamata, localizada na região sudoeste da llha de Kyushu, no Japão, que receberam altos índices de resíduos contaminados por $\mathrm{Hg}$ de uma fábrica de produtos químicos, em 1956 (26). A contaminação em Minamata alcançou graves proporções, uma vez que ao consumirem peixes e mariscos, mulheres grávidas tiveram seus fetos envenenados por metilmercúrio, os quais apresentaram importantes lesões cerebrais (26). Acidentes devido ao envenenamento por ingestão de farinha e semente de trigo contaminados com meHg e etHg também ocorreram no Iraque, Paquistão e Guatemala (27).

Os sintomas característicos da doença de Minamata incluem distúrbios como perda de sensibilidade nas extremidades das mãos, pés e ao redor da boca; ataxia; disartria; diminuição do campo visual; além de perturbações auditivas e tremores. Intoxicação grave pode causar cegueira, coma e morte (26)(27). Fetos expostos a baixos níveis de metilmercúrio exibiram retardo no desenvolvimento, além de disfunções sensoriais, neurológicas e motoras (14). Mais recentemente, em fevereiro de 2009, o Governing Council do United Nations Environment Programme (UNEP) iniciou os preparativos para a elaboração de um documento global e juridicamente vinculante sobre a utilização mundial do mercúrio, culminando com a Convenção de Minamata, aprovada em 19 de janeiro de 2013, na $5^{\circ}$ sessão do Comitê Intergovernamental de Negociação sobre o mercúrio em Genebra, e adotada em 10 de outubro do mesmo ano em Kukamoto, Japão, na Conference of Plenipotentiaries (28).

A redução das emissões antropogênicas de mercúrio e reemissões de mercúrio e compostos mercuriais representaram o ponto central de discussão na Convenção 
de Minamata, uma vez que ao ser introduzido antropogenicamente no ambiente, o Hg pode ser transportado por longas distâncias, promovendo bioacumulação nos ecossistemas e danos ao meio ambiente e à saúde humana (29). Fontes antropogênicas correspondem a $30 \%$ do mercúrio emitido anualmente para o ar, 10\% corresponde a fontes geológicas naturais e 60\% compreende as reemissões de mercúrio previamente acumulado no solo ou nos oceanos. Entende-se que grande parte do mercúrio reemitido (em ciclo no meio ambiente) teve como fonte as emissões antropogênicas, por isso, faz-se necessária a redução de tais emissões (30).

\subsection{ORGANOMERCURIAIS: METILMERCÚRIO E ETILMERCÚRIO}

O ambiente aquático é a principal via de contaminação com mercúrio para os seres humanos através do metilmercúrio, que pode ser encontrado em peixes, mamíferos marinhos (30), além de frutos do mar. O MeHg representa até $90 \%$ do mercúrio encontrado em peixes e possui elevado índice de absorção, cerca de 95\% ao ser ingerido (6). Em crianças, a toxicidade dos compostos de Hg são influenciados por fatores como a forma de exposição, seja tópica, oral, parenteral; pela dose, duração (aguda ou crônica); e o estágio de desenvolvimento (pré ou pós-natal). Contudo, a exposição ao $\mathrm{Hg}$ pode acontecer concomitantemente a mais de uma forma química ou com outras substâncias neurotóxicas (13).

A publicação da OMS (1996) Trace elements in human nutrition and health, aborda com preocupação as formas de contaminação por mercúrio através da ingestão de alimentos contaminados. A transferência de metilmercúrio pode ocorrer durante a gestação através da placenta para o feto e durante a lactação para o neonato. O documento aponta que a imaturidade do sistema digestivo pode acarretar absorção de metilmercúrio em níveis elevados, bem como baixos níveis de excreção, devido à imaturidade renal, ressaltando ainda o risco de absorção pelo sistema nervoso central nos estágios iniciais do desenvolvimento graças à imaturidade da barreira hematoencefálica $(31,32)$. 
Assim, entidades mundialmente reconhecidas emitiram informações sobre níveis de segurança toleráveis para exposição ao metilmercúrio, e estes servem como referência para o etilmercúrio (14). Os níveis de segurança são muito variáveis dependendo de cada agência. Para a OMS, os níveis de contaminação máxima por metilmercúrio não deveriam ultrapassar $3.3 \mu \mathrm{g} / \mathrm{kg}$ por semana, o que corresponde a 0,47 $\mu \mathrm{g} / \mathrm{kg} / \mathrm{dia}$ (31). A US Environmental Protection Agency (EPA) (33) recomenda que os níveis não excedam $0,1 \mu \mathrm{g} / \mathrm{kg}$ de peso corporal/dia. Outras agências que também possuem guias para regular a exposição ao meHg são o Food and Drug Administration (FDA) (34), e a US Agency for Toxic Substances and Disease Registry (ATSDR) (35).

Relatório da OMS emitido em 2012 afirma que de acordo com a farmacocinética do etilmercúrio em crianças, incluindo bebês prematuros e de baixo peso ao nascer, a meia-vida do etilmercúrio no organismo é curta, de 3 a 7 dias, sendo excretado nas fezes e retorna a níveis normais após 30 dias de vacinação (17). Semelhantemente, Pichichero et al (2002) verificaram em seu estudo descritivo que as concentrações de mercúrio no sangue sugerem meia-vida inferior a 10 dias, (mais curto que o metilmercúrio por via oral em adultos) e altos níveis de mercúrio nas fezes, apontando para a eliminação do etilmercúrio através do trato gastrointestinal em crianças (36).

Carneiro (2014) constatou que o etHg é transportado rapidamente do músculo para os tecidos e sua conversão em $\mathrm{Hg}$ inorgânico também ocorre de forma rápida (37). Evidências apontam para uma meia-vida de mercúrio inorgânico no cérebro humano de vários anos a décadas (38). Estudos experimentais apontaram uma meia-vida do Timerosal maior no cérebro do que no sangue em ratos (39). Os tecidos dos rins são um alvo potencial para os efeitos tóxicos advindos da exposição ao Timerosal, assim: "a vigilância contínua sobre a segurança do uso de Timerosal em vacinas é amplamente necessária, tal qual são as avaliações imparciais e de bom-senso de novas evidências sobre sua toxicidade" (37, p.64). 


\subsection{TIMEROSAL E O DUPLO PADRÃO DE SEGURANÇA ADOTADO PARA VACINAS PEDIÁTRICAS}

O Timerosal é um derivado mercurial utilizado por muito tempo como agente antisséptico e conservante em produtos cosméticos (40). Nos EUA, o Code of Federal Regulations (CFR) exige, desde 1968, a utilização de conservantes para frascos de vacinas multidoses (14). Apesar de serem usados de forma rotineira em todo o mundo como preservativo em vacinas multidoses, o uso de conservantes não elimina completamente o risco de contaminação das vacinas (14). Desde os anos de 1930 já existiam suspeitas de que o Timerosal seria uma substância potencialmente danosa à saúde e ineficiente como agente antimicrobiano (9).

Apesar de existirem substitutos para quase todas as formas de utilização do mercúrio, que possuem viabilidade econômica, custo-eficácia e segurança comprovados, e existir um alerta para que produtos livres de $\mathrm{Hg}$ sejam priorizados (6), o Timerosal continua sendo usado em vacinas de frascos multidoses de uso infantil. Assim, durante a Convenção de Minamata, as vacinas contendo Timerosal (VCT) foram excluídas da lista de produtos a serem regulamentadas.

O artigo 16 da Convenção abordou aspectos relacionados à saúde, considerando a proteção de vulneráveis e em situação de risco, além de orientações quanto à exposição ao mercúrio e compostos mercuriais. Entretanto, o documento faz referência a VCT apenas no seu anexo A, onde apresenta outros produtos que também estão fora da discussão, como produtos para proteção civil e uso militar e artigos usados em práticas religiosas (29).

Para Sykes et al (2014) a Convenção de Minamata institucionalizou o duplo padrão de segurança em vacinas como política global a partir da exclusão das VCT da lista de produtos contendo $\mathrm{Hg}$ a serem regulamentados: um padrão com vacinas livres ou reduzidas de Timerosal para os países centrais e outro de VCT para os países periféricos (9). Em 2012, ao reafirmar a segurança no uso do Timerosal como conservante de vacinas, defendendo a sua utilização, a OMS concluiu que seu uso permite que pessoas em todo o mundo tenham acesso facilitado às vacinas (17). 
A motivação para o início da retirada de VCT de uso pediátrico nos EUA, a partir de 1999, foi o risco provável da exposição infantil a doses cumulativas de Timerosal presente nas vacinas administradas ao longo dos seis primeiros meses de vida, que excediam os níveis limítrofes de segurança proposto pelo EPA. Variáveis como calendário de imunização, formulação da vacina e peso corporal dos bebês podem gerar uma exposição aumentada para o mercúrio (41). Desta forma, nos EUA, as vacinas administradas a crianças de até 6 anos eliminaram o Timerosal e algumas podem conter apenas traços do elemento, o que corresponde a 1 micrograma ou menos de mercúrio por dose, exceto a vacina inativada contra Influenza, que permanece em uso e contém mercúrio em sua composição (14).

Dados científicos endossam o risco de danos do etHg nos estágios iniciais da vida para cérebro de crianças, sobretudo os mais vulneráveis (12), a exemplo de recém-nascidos prematuros. Estudos in vitro e in vivo têm demonstrado que concentrações VCT são relevantes para afetar o SNC em desenvolvimento $(42,43)$. Assim, verificou-se a existência de plausibilidade para o risco de toxicidade por exposição a baixas doses de mercúrio, ao menos em crianças mais sensíveis (44). De forma coletiva, os estudos avaliados por Dórea (2010) apontam risco aumentado para danos neurocomportamentais, compatíveis com baixas doses de $\mathrm{Hg}$ (12).

Ademais, o etilmercúrio pode desencadear efeitos transitórios para o SNC passíveis de ocorrer longos períodos após a exposição (10). Para além do risco de danos ao SNC, o Timerosal é considerado um dos mais prevalentes alérgenos de contato (45), tendo sido constatado que países como a Áustria, Dinamarca, Polônia, Grécia e EUA verificaram a diminuição de reações alérgicas após a retirada do Timerosal das vacinas infantis (46). 


\subsection{TIMEROSAL E VACINAS EM FRASCOS MULTIDOSES}

O Timerosal, utilizado como conservante de vacinas multidoses para prevenir contaminação bacteriana, não é necessário para vacinas em frascos de dose única. Vacinas multidoses são preferencialmente vendidas aos países periféricos graças ao argumento de baixo custo de produção (47). Porém, um dos maiores problemas das vacinas multidoses é a questão do desperdício, pois uma vez aberto o frasco, a vida útil da vacina dura por um intervalo de tempo limitado (48). Ademais, cada vez que nova agulha é inserida no frasco, a chance de contaminação da vacina aumenta, o que gera riscos de contaminação para o receptor da vacina (49).

As vacinas sob apresentação de frascos multidoses em discussão neste trabalho administradas a bebês de até seis meses de idade são a Hepatite $\mathrm{B}$, a Pentavalente e a Influenza. Segundo informações da Secretaria de Estado de Saúde do Distrito Federal (DF), a vacina contra Hepatite B fornecida no DF é fabricada pelo Instituto Butantan em apresentações de 10 doses por frasco, com validade de 15 dias após aberta. A vacina Pentavalente é fabricada pelos laboratórios Novartis e Serum Institute of India, e ambos são de uso imediato após abertura do frasco. A vacina Influenza é fabricada pelo laboratório Glaxo Smith Kline (GSK), contendo 10 doses por frasco e validade de 7 dias, conforme Anexo A.

As vacinas Hepatite $B$ e Influenza acima referidas também são administradas a gestantes, além da vacina Dupla Adulto (dT). O laboratório responsável pela fabricação da dT é o Instituto Butantã, em apresentações de frascos contendo 10 doses e prazo de validade de 15 dias após a abertura do frasco (Anexo A). De acordo com o Manual de Normas e Procedimentos para Vacinação no Brasil, os frascos de vacinas multidoses que excederem o prazo de validade devem ser desprezados e registro no formulário padronizado deve ser efetuado para que seja possível quantificar as perdas dos imunobiológicos (1).

Como alternativa para o gerenciamento de perdas de vacinas, algumas unidades de saúde pública no DF têm limitado o número de pacientes e reservado dias específicos para a administração de vacinas contra a Febre Amarela (FA) e 
Bacilo de Calmette \& Guérin (BCG), como é o caso das unidades da região Centro Norte de Brasília, que compreendem as unidades de saúde no Lago Norte, Asa Norte, Cruzeiro e Varjão, conforme Anexo B. Embora as vacinas para FA e BCG sejam vacinas reconstituídas e não possuam Timerosal em sua composição, cabe o registro de que a primeira é fabricada pelo Instituto Butantan, em frascos de 5 e 10 doses e a BCG é fabricada pelo laboratório Fundação Ataulpho de Paiva, em frascos de 10 doses, ambas com vida útil de 6 horas (Anexo $A$ ).

Vacinas monodoses permitem uma maior oportunidade de vacinação, enquanto as vacinas multidoses podem gerar margem para que o profissional de saúde seja relutante de abrir um frasco multidose para poucos pacientes, o que pode acarretar diminuição da cobertura vacinal, por perda de oportunidade e consequentemente, diminuição da cobertura (48). Vacinas em apresentação de dose única oferecem maior segurança no manuseio e evitam desperdício (48) e, por isso, têm se tornado uma tendência mundial, sobretudo para àquelas de alto valor agregado (50). Vacinas em dose única são capazes de impedir desperdício da vacina, mas como desvantagem podem gerar maior produção de resíduos médicos (49). 


\section{FUNDAMENTAÇÃO TEÓRICA - A BIOÉTICA}

\subsection{BREVE HISTÓRICO}

O termo Bioética foi utilizado pela primeira vez em 1970 por Van Rensselaer Potter, que em janeiro de 1971, publicou o livro "Bioethics: a Bridge to the Future" (51). Potter propunha um diálogo entre as ciências e as humanidades por meio de uma visão ampliada de macrobioética. Seis meses após a publicação de Potter, em julho de 1971, André Hellegers, da Universidade de Georgetown, utilizou o termo para nominar o Joseph and Rose Kennedy Institute for the Study of Human Reproduction and Bioethics. Contrapondo-se à macrobioética de Potter, a bioética de concepção hellegeriana abrangia questões de microbioética ou de bioética clínica $(52,53)$.

Cabe destacar que apesar dos esforços para a redução de danos aos sujeitos de pesquisa, Beecher (1966) concluiu que práticas danosas e degradantes continuavam sendo realizadas, mesmo após a elaboração de documentos norteadores para pesquisas envolvendo seres humanos, como a Declaração de Helsinki e o Código de Nuremberg (54). Assim, em 1974, o Governo dos EUA criou a Commission for the Protection of Human Subjects of Biomedical and Behavioral Research, com o objetivo de regulamentar pesquisas envolvendo seres humanos, especialmente após a publicização de três casos que originaram relevante impacto entre a opinião pública daquele país: injeção de células cancerosas em idosos doentes em Nova York (1963); inoculação de hepatite viral em crianças portadoras de retardo mental entre 1950 e 1970; e o caso Tuskegee no Alabama (1932 a 1972), no qual 400 negros portadores de sífilis foram mantidos sem tratamento, mesmo após a descoberta da penicilina (55).

Após quatro anos de sua instituição, a Comissão publicou o Relatório Belmont (56), apresentando três princípios básicos a serem observados em pesquisas envolvendo seres humanos: o respeito às pessoas, a beneficência e a justiça. Em 1979, Tom Beauchamp, que fora membro da comissão redatora do relatório Belmont, publicou com James Childress a primeira versão de Princípios da Ética Biomédica (Principles of 
Biomedical Ethics) (57). Assim, a bioética hellegeriana do Instituto Kennedy ganhou notoriedade e amplitude mundial caracterizando o que hoje se conhece como a Bioética Principialista. O "Principialismo" apropriou-se dos três princípios do Relatório Belmont: respeito às pessoas - agora definido como Respeito à autonomia; Beneficência, diferenciando-o da Não Maleficência e o Princípio da Justiça - aplicando-os a questões de prática clínica e assistencial $(57,58)$.

Em 1988, insatisfeito com o reducionismo da Bioética a questões biomédicas, Potter ampliou sua própria definição de bioética, que foi difundida no congresso mundial da International Association of Bioethics (IAB) em Tóquio propondo uma "Bioética Global”. Assim, o IV Congresso Mundial de Bioética, realizado em 1998 pelo IAB com o título Global Bioethics foi marcado pelo resgate das ideias de Potter relacionados com a Bioética Global, iniciando uma nova fase para a Bioética, com ampliação de temas para além das questões biomédicas (53).

Nesse contexto, o VI Congresso Internacional de Bioética da IAB, cujo título foi "Bioética: poder e injustiça", realizado em 2002 na cidade de Brasília, patrocinado pela Sociedade Brasileira de Bioética e organizado pelo Núcleo de Estudos e Pesquisas em Bioética da UnB (hoje Cátedra Unesco de Bioética), representou um marco fundamental para a Bioética brasileira e mundial. O Congresso promoveu a ênfase ao pluralismo moral; ampliação e maior visibilidade para as questões sanitárias, sociais e ambientais, sobretudo as discrepâncias sociais e econômicas constatadas nos países periféricos $(59,60)$.

Assim, sob a influência da Bioética crítica e dialética brasileira, a Sociedade Brasileira de Bioética e, logo a seguir, a Rede Latino-Americana e do Caribe de Bioética da Unesco (Redbioética) tiveram um papel de especial importância na ampliação e politização da agenda bioética internacional, que culminou com a homologação da DUBDH (59). Barbosa (2006) afirma que o Brasil como país e como nação contribuiu para a construção de uma declaração politizada, atenta a questões sociais, sanitárias e ambientais, constatadas especialmente nos países do hemisfério sul (61). Desta forma, a DUBDH ${ }^{1}$ elenca princípios que são pertinentes à discussão sobre duplo padrão de segurança em vacinas infantis, a saber:

1 DUBDH: Tradução e revisão final sob a responsabilidade da Cátedra UNESCO de Bioética da Universidade de Brasília (UnB) e da Sociedade Brasileira de Bioética (SBB). 
Artigo 4 - Benefício e Dano: Os benefícios diretos e indiretos a pacientes, sujeitos de pesquisa e outros indivíduos afetados devem ser maximizados e qualquer dano possível a tais indivíduos deve ser minimizado, quando se trate da aplicação e do avanço do conhecimento científico, das práticas médicas e tecnologias associadas.

Artigo 8 - Respeito pela Vulnerabilidade Humana e pela Integridade Individual: A vulnerabilidade humana deve ser levada em consideração na aplicação e no avanço do conhecimento científico, das práticas médicas e de tecnologias associadas. Indivíduos e grupos de vulnerabilidade específica devem ser protegidos e a integridade individual de cada um deve ser respeitada.

Artigo 10 - Igualdade, Justiça e Equidade: A igualdade fundamental entre todos os seres humanos em termos de dignidade e de direitos deve ser respeitada de modo que todos sejam tratados de forma justa e equitativa.

\subsection{BIOÉTICA DE INTERVENÇÃO}

A Bioética de Intervenção desenvolveu-se na Cátedra Unesco de Bioética da Universidade de Brasília e possui como marco de seu nascimento a conferência apresentada pelo Prof. Volnei Garrafa no IV Congresso Argentino de Bioética, realizado em Mar Del Plata, em 1998 (62). O termo Bioética de Intervenção foi cunhado pela primeira vez na conferência de abertura do I Congresso Boliviano de Bioética, em La Paz, no ano de 2001 (62), e possui como documento referencial o texto Intervention Bioethics: a Proposal for Peripheral Countries in a Context of Power and Injustice, proferido na conferência de abertura do VI Congresso Internacional de Bioética da IAB em Brasília, em 2002 (19).

Segundo a $\mathrm{BI}$, o processo de globalização da economia mundial ampliou as desigualdades entre países centrais e periféricos, gerando assimetrias entre as populações, através da concentração de riquezas para poucos, e vulnerabilizando cada vez mais os países periféricos (63). Essa nova proposta epistemológica de enfoque e utilização da bioética, a $\mathrm{Bl}$, classifica países centrais como àqueles nos quais questões básicas de saúde, educação, moradia, alimentação e transporte já foram solucionados; enquanto periféricos são os países comumente denominados "em desenvolvimento", nos quais suas populações convivem rotineiramente com problemas de exclusão social, concentração de riqueza, pobreza, miséria, evasão de 
divisas para países centrais e exclusão de vulneráveis (64).

Partindo de uma visão crítica, dialética, e socialmente comprometida, a BI significa uma proposta anti-hegemônica (65) às abordagens tradicionais da Bioética de caráter biomédico e biotecnológico, sobretudo o Principialismo (18). A Bioética de Intervenção propõe que os países periféricos avaliem suas questões e macroproblemas sanitários, sociais e ambientais a partir de percepções próprias, não importando de modo acrítico e vertical padrões éticos alheios à realidade local e incapazes de solucionar questões persistentes neles existentes (19).

As bases epistemológicas da BI se fundamentam sobre os conceitos de um utilitarismo consequencialista e solidário, definindo que as políticas públicas e os processos de tomada de decisão alcancem o maior número de pessoas possível, pelo maior espaço de tempo, alcançando os melhores resultados coletivos, ainda que em detrimento de algumas situações individuais. Entre seus tópicos de focagem e referenciais de ação, podem ser citados os seguintes: corporeidade; direitos humanos contemporâneos; os "quatro pês" indispensáveis ao desenvolvimento de práticas responsáveis e éticas (prevenção de danos e iatrogenias; precaução frente ao desconhecido; prudência em relação aos avanços tecnológicos; e proteção das pessoas mais vulneráveis). Inclui, também, a utilização e ampliação conceitual de termos como o empoderamento, a libertação e a emancipação $(19,64)$.

\subsection{PREVENÇÃO DE DANOS E O PRINCÍPIO DA PRECAUÇÃO}

Alguns pontos específicos relacionados com a Bioética são de especial interesse para os propósitos da presente dissertação, entre eles, por exemplo, a prevenção de danos e a precaução, que fazem parte do contexto dos "Quatro Pês" descritos na Bioética de Intervenção $(64,19)$. O art. $4^{\circ}$ da DUDBH, por sua vez, aborda o tema do Benefício e Dano, com vistas à redução de efeitos e problemas indesejados advindos da aplicação de práticas sanitários e outras. Seguindo a mesma linha de reflexão, a World Commission on the Ethics of Scientific Knowledge 
and Technology (COMEST), órgão consultivo da UNESCO, elaborou, em 2005, um documento específico que trata sobre o Princípio da Precaução (PP). O Princípio da Precaução ou Vorsorgeprinzip, originado nos anos 1970, recebeu variadas definições em tratados e acordos internacionais ao longo dos anos, representando uma estratégia no manejo de questões que possuem algum nível de incerteza científica (66).

Em 1992, na Conferência das Nações Unidas realizada no Rio de Janeiro sobre meio ambiente e desenvolvimento, foi elaborado o primeiro documento internacional reconhecendo formalmente o PP (67). O Princípio da Precaução teve sua origem na discussão a respeito das leis ambientais, porém, tem sido utilizado extensivamente em questões referentes ao comércio, segurança alimentar, e à redução de danos na saúde pública $(68,66)$. Graças a sua importância como um princípio ético, com um escopo amplo e norteador na tomada de decisões em políticas públicas, a COMEST elaborou um documento sobre o tema que possui como base a fundamentação ética.

O Princípio da Precaução parte de uma reflexão explícita e filosófica sobre crenças e práticas morais, no qual ações e omissões são tratadas de igual modo. A definição para PP elaborada pela COMEST, afirma que se uma atividade é capaz de produzir dano moralmente inaceitável, cientificamente plausível, porém incerto, deve-se agir para evitar ou minimizar o provável dano (66). Assim:

\footnotetext{
Quando atividades humanas podem gerar dano moralmente inaceitável que é cientificamente plausível mas incerto, ações devem ser tomadas para evitar ou diminuir o dano. Dano moralmente inaceitável se refere àquele que pode prejudicar seres humanos ou o meio ambiente: ameaçando a vida humana ou a saúde; sério ou irreversível; injusto para apresentar às futuras gerações ou imposto sem considerar os direitos humanos daqueles afetados. A plausibilidade deve ser fundamentada na análise científica e as ações se referem a intervenções que devem ocorrer antes que o dano ocorra, para evitá-lo ou minimizá-lo (66, p.14) (tradução livre).
}

Diversos países têm se utilizado do Princípio da Precaução para a formulação de políticas públicas nas áreas sanitária e ambiental (69). O referido princípio foi detalhado no artigo 191 do Tratado sobre o funcionamento da União Europeia, requerendo ação imediata frente ao risco potencial de dano à saúde humana, animal e vegetal, bem como à proteção do meio ambiente (70). Nos EUA, o princípio ganhou 
abrangência a partir da Conferência de Wingspread, em 1998 (71), onde foi definido que se uma atividade representa dano ao meio ambiente ou à saúde humana, medidas de precaução devem ser tomadas ainda que relações de causa e efeito não estejam completamente elucidadas cientificamente. A Declaração agregou pela primeira vez quatro elementos de precaução: ações rápidas mesmo em face da incerteza científica; transparência; avaliação de alternativas; e inversão do ônus de segurança ao proponente de uma atividade potencialmente danosa (72).

Nesse sentido, o Princípio do Benefício e Dano da DUBDH dialoga com o Princípio da Precaução, através da busca pela prevenção de danos. O texto da DUBDH afirma que os benefícios a pacientes e sujeitos de pesquisa, sejam diretos ou indiretos, devem ser maximizados, frente a possíveis danos, que devem ser reduzidos, seja nas abordagens de práticas médicas ou quando da aplicação dos avanços científicos (24). Para Dallari e Ventura, os danos devem ser previstos antes mesmo da possibilidade da existência de risco (73). O conhecido Juramento de Hipócrates já previa na antiguidade a obrigação de não causar dano e promover benefícios: "Usarei o tratamento para ajudar o doente de acordo com a minha habilidade e com meu julgamento, mas jamais o usarei para lesá-lo ou prejudicá-lo" (58, p. 209).

O tema da prevenção de danos tem sido abordado ao longo dos séculos sob várias perspectivas, em especial no campo da saúde. William David Ross, nas primeiras décadas do século $X X$, desenvolveu uma ética normativa baseada em deveres - prima facie duties, dentre os quais estão os deveres de beneficência e da não-maleficência. Os dois deveres seriam independentes e não absolutos, condicionados diante da necessidade de se fazer escolhas (74). William Frankena, por sua vez, trata os princípios da Não-maleficência e da Beneficência diferentemente de Beauchamp e Childress, como um único princípio, porém, o decompõe em quatro obrigações gerais, organizando-os hierarquicamente, a saber: não infligir males ou danos, que corresponderia à não maleficência; impedir que ocorram males ou danos; eliminar males ou danos; e fazer ou promover o bem. Desta forma, numa situação de conflito, o primeiro elemento teria precedência sobre o segundo e assim por diante (75). 


\subsection{IMPERIALISMO MORAL NO DUPLO PADRÃO DE VACINAS}

\subsubsection{Considerações Gerais}

Bobbio et al (2004) definem imperialismo como:

Expansão violenta por parte dos Estados, ou de sistemas políticos análogos, da área territorial da sua influência ou poder direto, e formas de exploração econômica em prejuízo dos Estados ou povos subjugados, geralmente conexas com tais fenômenos (76, p. 611).

Para Garrafa (2008), o imperialismo moral, no campo da bioética, pode ser manifestado através de diferentes formas e impositivamente, através da tentativa de sobrepor padrões morais de uma dada cultura, região geopolítica ou países a outrem. O tema é muito abrangente e pode alcançar questões relativas à educação, liberdade, política e outros (77).

O imperialismo econômico advindo dos países ricos, ou centrais, gera sobre os países periféricos uma situação que alguns autores denominam imperialismo moral (78). A Bioética crítica tem discutido a abordagem do imperialismo ético em face das alterações na Declaração de Helsinki, da World Medical Association (WMA), documento normativo internacional balizador da ética na pesquisa envolvendo seres humanos (79). A $7^{a}$. versão da Declaração de Helsinki, foi elaborada na $64^{\circ}$ Assembleia geral da WMA, realizada em Fortaleza, Brasil, em outubro de 2013 (80), cujo ponto central de repercussão tem gerado críticas a respeito da nova redação da Declaração, que abre precedente para a existência de duplo padrão em pesquisas clínicas, ao permitir a utilização de placebo, mesmo em face da existência de terapia eficaz (81).

Entretanto, a DUBDH, considera que: "todos os seres humanos, sem distinção, devem se beneficiar dos mesmos elevados padrões éticos na medicina e 
nas pesquisas em ciências da vida" (24, preâmbulo). Compartilhando esta percepção, Hellmann et al (2014) consideram que a equidade em saúde precisa ser uma prioridade, e por conseguinte, a existência de um padrão ético único para pesquisa médica com seres humanos (81). A partir de um paralelo com o duplo padrão em pesquisas envolvendo seres humanos, citado por Nascimento e Martorell (2013) como uma forma de colonização da vida, aqui é exposta a utilização do duplo padrão em vacinas infantis (82). O trecho a seguir, de Garrafa e Prado (2001), foi escrito como uma crítica às mudanças na Declaração de Helsinki ao abordar questões de imperialismo econômico e ético, mas será aplicado à questão do duplo padrão de segurança em vacinas, uma vez que ambos seguem o mesmo contexto de ações e práticas verticalizadas e impositivas.

\begin{abstract}
A lição a ser tirada de toda essa história é que, mais uma vez, alguns países ricos, com o apoio de poderosos complexos empresariais internacionais de medicamentos e bioderivados interessados quase que exclusivamente no mercado e no lucro, tentam fazer valer seu poder (econômico) de pressão e persuasão, em detrimento da priorização pelo social, da inclusão dos sujeitos sociais no campo verdadeiramente democrático com consequente usufruto dos benefícios do mundo contemporâneo. Em uma era de globalização e fundamentalismo econômico, tenta-se, por intermédio de uma imensa assimetria científica e tecnológica, impor um imperialismo ético às nações mais pobres. Além da histórica importação acrítica e unilateral de ciência e tecnologia das nações mais fortes para aquelas mais frágeis, sem levar em consideração o contexto socioeconômico e cultural destas, "agora tenta-se", também, "a importação acrítica e vertical", de cima para baixo, "de ética" (78, p. 1493).
\end{abstract}

\title{
3.4.2 Imperialismo Moral e o Mercado de Vacinas
}

O orçamento do Programa Nacional de Imunizações no Brasil cresceu mais de $140 \%$ entre os anos de 2010 a 2015, passando de $R \$ 1,2$ bilhão (2010) para $R \$$ 2,9 bilhões (2015) (83). Entretanto, o sistema frágil do processo de tomada de decisões dos países periféricos é explorado pelos fabricantes de vacinas, conhecedores do potencial de mercado desses países, com elevado índice populacional e poder de compra variável (84). Para além dos fabricantes, organizações internacionais como a OMS e a Global Alliance for Vaccines and 
Immunization (GAVI) promovem a introdução de novas vacinas, mesmo quando populações periféricas ainda convivem com doenças "antigas" e não completamente controladas ou erradicadas, tais como difteria, tétano, coqueluche, sarampo $(84,85)$ e a febre amarela.

O GAVI representa uma parceria global entre os setores público e privado. É composto por organizações como a OMS, o Fundo das Nações Unidas para a Infância (UNICEF), o Banco Mundial, a Fundação Bill e Melinda Gattes, fabricantes de vacinas e institutos de pesquisa, como o Institut Pasteur, França; a indústria farmacêutica de países centrais e periféricos; e os governos dos países periféricos, que são cofinanciadores de novas vacinas introduzidas no calendário de vacinação $(86,87)$. Além da pressão exercida pelos fabricantes de vacinas sob os países periféricos (88), organismos como a OMS também influenciam tais países na tomada de decisões, ao passo que organizações como a GAVI, financiam os custos iniciais de inserção de novas vacinas nos programas nacionais de imunização, em formato de doação, "persuadindo" os governos a adicionarem novas vacinas no calendário nacional $(88,89)$.

Equações de custo-benefício, por exemplo, podem ser tendenciosas, supervalorizando a perspectiva de benefício das vacinas, desvalorizando informações sobre seus custos e a real necessidade de inserção de vacinas nos programas nacionais, para promover interesses de fabricantes de vacinas, contrapondo-se à necessidade baseada em dados epidemiológicos reais (90). Puliyel (2011) argumenta que vacinas não deveriam ser inseridas no programa nacional de imunizações sem que houvesse comprovada necessidade. Vacinas foram inseridas no programa de vacinação na Índia quando o número de mortes causadas pela doença não possuía representatividade, gerando alto impacto financeiro aos cofres públicos (91).

A estratégia global das multinacionais inclui a busca do monopólio tecnológico, a ampliação do portfólio e o domínio de mercado. Estabelece grande capacidade de produção nos países centrais, de tal forma a atender a demanda dos países desenvolvidos e manter o poder de definir o preço e conquistar novos mercados e obter maior retorno financeiro no menor tempo possível. Por sua vez, as grandes multinacionais estão também organizando institutos sem fins lucrativos, voltados para pesquisa e desenvolvimento de vacinas, com foco em produtos de interesse para os países em 
desenvolvimento, como os orientados para doenças tropicais negligenciadas, infecciosas e parasitárias. Tais iniciativas denotam o interesse das multinacionais em melhorar sua imagem junto à sociedade (50, p. 451).

Há que se pesquisar mais sobre o financiamento de vacinas, sobretudo a criação de institutos autodeclarados sem fins lucrativos, criados para desenvolver vacinas que atendam as doenças negligenciadas dos países periféricos, tal qual a empresa Novartis Vaccines for Global Health Institute (NVGH), instituto criado por um grande fabricante de vacinas, destinado a produzir vacinas supostamente não rentáveis para doenças dos países periféricos (92). Os elevados investimentos em inovação tecnológica têm gerado alta lucratividade e retorno em curto prazo, estimulando as multinacionais a lançar novos produtos com elevado valor agregado. Com isso, vacinas de baixo custo tornaram-se negligenciadas, gerando desabastecimento e abrindo mercado para laboratórios de países em desenvolvimento, como laboratórios da Índia, que passaram a manufaturar tais produtos de pequeno valor agregado $(50,93)$.

A respeito do mercado de vacinas administradas na rede pública de saúde, no Brasil, enquanto as vacinas Hepatite B, Pentavalente e Influenza são acondicionadas em frascos multidoses, as vacinas comercializadas na rede privada de imunização são acondicionadas exclusivamente em frascos monodoses. A vacina Hexavalente na rede privada substitui a Pentavalente fornecida pelo SUS, porém, está em falta nas clínicas particulares desde o ano de 2015, com previsão de normalização da oferta apenas em 2017. Uma das clínicas consultadas no DF informou a disponibilidade de pequeno lote da vacina Hexavalente disponível ao custo de $\mathrm{R} \$ 690,00$ (seiscentos e noventa reais/dose) e reafirmou que a normalização no fornecimento da vacina estava previsto para 2017 (Anexo C) ${ }^{2}$.

Cada cartucho da vacina adsorvida de Hepatite B recombinante produzida pelo Instituto Butantan, de São Paulo, Brasil, contém 20 frascos, correspondendo a 10 doses de 0,5 mL. (94) e é comercializado ao Governo pelo valor máximo de até $\mathrm{R} \$$ $6.513,19$ (seis mil, quinhentos e treze reais e dezenove centavos). Assim, cada dose

2 Foram consultadas via ligação telefônica as clínicas de Imunização: Imunizare, em Teresina; e Sabin Vacinas no Distrito Federal (DF), em 07/11/2016 e consulta via e-mail com a clínica Imunocentro (DF) em 09/10/2016. 
custa $R \$ 32,56$ (trinta e dois reais e cinquenta e seis centavos) (95). Entretanto, a vacina para Hepatite $B$, em seringa de dose única, fabricada pelo laboratório GSK contendo $10 \mu \mathrm{g} / 0,5 \mathrm{~mL}$, e semelhantemente indicada para o uso em recém-nascidos, bebês, crianças e adolescentes com até 19 anos de idade, consta na lista de preços máximos de medicamentos por princípio ativo para compras públicas ao custo máximo de $R \$ 30,41$ (trinta reais e quarenta e um centavos) de venda ao governo (96). O valor por dose pesquisado na rede privada na cidade de Teresina-PI é de $\mathrm{R} \$ 90,00$ (noventa reais), enquanto em Brasília/DF a dose é comercializada por $\mathrm{R} \$$ 120,00 (cento e vinte reais). 


\section{OBJETIVOS}

\subsection{OBJETIVO GERAL:}

Promover uma análise bioética a respeito da exposição intencional ao mercúrio em vacinas, agravando desnecessariamente a exposição de fetos, recémnascidos e prematuros a neurotóxicos nos países periféricos.

\subsection{OBJETIVOS ESPECÍFICOS:}

4.2.1. Elencar as vacinas administradas até os seis meses de idade e durante o período gestacional, que contém Timerosal em sua composição, de acordo com o calendário do programa nacional de imunização brasileiro.

4.2.2. Pesquisar a ocorrência de contradições que revelem o duplo padrão em vacinas nos países periféricos, a partir da análise dos documentos abaixo relacionados: Joint Statment of the American Academy of Pediatrics and the United States Public Health Service, 1999; e The Safety of Thiomersal, OMS, 2012.

4.2.3. Analisar a questão moral e ética relacionada ao mercado de vacinas contendo Timerosal nos países periféricos, a partir do conceito de imperialismo moral, da Bioética de Intervenção e a Declaração Universal sobre Bioética e Direitos Humanos. 


\section{MÉTODO}

Trata-se de uma pesquisa qualitativa, realizada por meio da análise de conteúdo pré selecionado de literatura (97). A amostra documental escolhida consistiu dos seguintes documentos: Calendário do Programa Nacional de Imunizações (PNI) (98); e Manual de Normas e Procedimentos para Vacinação do Ministério da Saúde (1), além de outras normativas do Ministério da Saúde, que se relacionam ao tema da vacinação infantil.

O Manual de Normas e Procedimentos para Vacinação do Ministério da Saúde, de 2014 (1), apresenta um panorama das vacinas que compõem o calendário do Programa Nacional de Imunizações (PNI) (98). Assim, a primeira parte dos resultados elenca as vacinas administradas no Brasil desde o período gestacional (fetos) e do nascimento até os seis meses de idade.

A segunda parte dos resultados correspondeu a uma análise de dois documentos norteadores que se referem à eliminação e/ou manutenção do Timerosal como conservante de vacinas infantis: Joint Statment of the American Academy of Pediatrics (AAP) and the United States Public Health Service (USPHS), 1999 (15); e The Safety of Thiomersal, OMS, 2012 (17). Tais documentos foram avaliados no que concerne às contradições sobre a utilização do Timerosal nos países periféricos e sua eliminação nos países centrais, a partir dos textos originais em inglês, recebendo livre tradução.

A escolha do documento Joint Statment of the AAP and the USPHS deveu-se ao fato de ter sido este o primeiro documento recomendando a eliminação do Timerosal em vacinas infantis. O documento The Safety of Thiomersal, por sua vez, foi escolhido por se tratar de uma publicação da OMS, uma entidade respeitada mundialmente e responsável por coordenar programas de vacinação global (54). O propósito foi pesquisar a ocorrência de contradições que legitimem o duplo padrão em vacinas nos países periféricos. A pesquisa foi de baixo custo e não houve necessidade de submissão ao Comitê de Ética em Pesquisa, uma vez que não envolveu diretamente seres humanos ou animais. 


\section{RESULTADOS E ANÁLISE}

Esta seção elenca quais são as vacinas que fazem parte do calendário de vacinação nacional, vigente no ano de 2016, que contém mercúrio em sua composição e são administradas durante o período gestacional, e por conseguinte, durante a vida intrauterina do feto; e desde o nascimento de bebês até os primeiros seis meses de vida, incluindo prematuros. Na sequência, foram analisados os seguintes documentos: Joint statement of the American Academy of Pediatrics (AAP) and the United States Public Health (USPHS), publicado em 1999; e The Safety of Thiomersal, publicação da Organização Mundial de Saúde, em 2012.

\subsection{VACINAS CONTENDO TIMEROSAL ADMINISTRADAS DESDE O NASCIMENTO ATÉ OS SEIS PRIMEIROS MESES DE VIDA E DURANTE O PERÍODO GESTACIONAL}

As vacinas Hepatite B recombinante (ao nascer) e a Pentavalente (2, 4 e 6 meses) são vacinas do PNI administradas a partir do nascimento até os seis meses de idade que contêm Timerosal como conservante, fornecidas em frascos multidoses na rede pública de saúde. A vacina Influenza também faz parte do calendário nacional de vacinação do Sistema Único de Saúde (SUS), e deve ser administrada a partir dos seis meses de vida, em duas doses até os oito anos de idade (99). Assim, bebês que completam seis meses de vida coincidindo com o período da campanha anual de vacinação para Influenza, são expostos concomitantemente a duas vacinas contendo Timerosal: a Pentavalente e a Influenza. A segunda dose da vacina é administrada com intervalo de 30 dias. 
Quadro 1 - Vacinas que contém Timerosal recomendadas pelo Programa Nacional de Imunização do Brasil às crianças de 0 a 6 meses de vida, doses e características

\begin{tabular}{|l|l|l|}
\hline \multicolumn{1}{|c|}{ VACINAS } & \multicolumn{1}{|c|}{ DOSES } & \multicolumn{1}{c|}{ CARACTERÍSTICAS } \\
\hline Hepatite B & 1 & $\begin{array}{l}\text { Administrada a recém-nascidos nas primeiras 24 horas de } \\
\text { vida, preferencialmente nas 12 primeiras horas, ou em até } \\
30 \text { dias nos serviços de saúde. }\end{array}$ \\
\hline Pentavalente & 3 & $\begin{array}{l}\text { A vacina adsorvida difteria, tétano, pertússis, hepatite b } \\
\text { (recombinante), Haemophilus influenzae b (conjugada) - } \\
\text { Pentavalente. Deve ser administrada aos dois, quatro e } \\
\text { seis meses de idade. }\end{array}$ \\
\hline Influenza & 2 & $\begin{array}{l}\text { Administrada aos seis meses de vida, em duas doses até } \\
\text { os oito anos de idade. }\end{array}$ \\
\hline
\end{tabular}

Fonte: Adaptado do Calendário do Programa Nacional de Imunizações (2016) e Manual de Normas e Procedimentos para Vacinação do Ministério da Saúde (2014).

As vacinas Hepatite $b$ recombinante, Dupla Adulto e Influenza são administradas a mulheres grávidas, independente da idade gestacional $(1,99)$.

Quadro 2 - Vacinas que contém Timerosal recomendadas pelo Programa Nacional de Imunização do Brasil a gestantes, doses e características

\begin{tabular}{|l|l|l|}
\hline VACINAS & DOSES & CARACTERÍSTICAS \\
\hline Hepatite B & $1-3$ & $\begin{array}{l}\text { Administrada em qualquer faixa etária e idade gestacional, até 3 } \\
\text { doses, a depender da situação vacinal. }\end{array}$ \\
\hline $\begin{array}{l}\text { Dupla adulto }-1-3 \\
\text { vacina } \\
\text { adsorvida } \\
\text { difteria e tétano } \\
\text { adulto }\end{array}$ & $\begin{array}{l}\text { Administrada em até três doses de acordo com a situação vacinal } \\
\text { e pode ser administrada em qualquer idade gestacional, sendo a } \\
\text { última dose em até vinte dias antes da data provável do parto. }\end{array}$ \\
\hline \begin{tabular}{l} 
Influenza \\
\hline
\end{tabular} & 1 & Administrada em qualquer idade gestacional. \\
\hline
\end{tabular}

Fonte: Adaptado do Calendário do Programa Nacional de Imunizações (2016) e Manual de Normas e Procedimentos para Vacinação do Ministério da Saúde (2014). 


\subsection{ANÁLISE DO DOCUMENTO JOINT STATMENT OF THE AMERICAN} ACADEMY OF PEDIATRICS AND THE UNITED STATES PUBLIC HEALTH, 1999.

O documento, publicado em 1999, representou um marco para a eliminação do Timerosal em vacinas nos Estados Unidos e consequentemente, em outros países. De acordo com a declaração, não existem evidências ou informações de que crianças possam sofrer qualquer dano ao serem submetidas à exposição ao Timerosal seguindo o calendário de vacinação, pois, segundo o documento, existe uma margem de segurança para as exposições ao mercúrio, decorrentes do calendário vigente.

Entretanto, o ponto central do documento parte da premissa de que algumas crianças podem ser expostas a níveis cumulativos de mercúrio ao longo dos seis primeiros meses de vida, excedendo os níveis de segurança para o metilmercúrio, propostos pela EPA. Assim, devido ao risco em potencial, o USPHS em conjunto com a AAP e os fabricantes das vacinas concordaram que exista uma urgência em substituir as vacinas contendo Timerosal por outras sem o conservante. Da mesma forma, agências regulatórias europeias, a comissão europeia de fabricantes de vacinas e o FDA concordaram pelo banimento do Timerosal em vacinas. Ainda assim, o documento reforça a ideia de que o risco de exposição cumulativa ao Timerosal, em bebês de até seis meses de idade, é inferior ao risco de se contrair doenças ou a gravidade de mortes que podem ser causadas pela abstenção ao programa de vacinação.

\subsubsection{Situação Específica de Recém-Nascidos Prematuros e de Baixo Peso}

O documento informa que existe uma margem de tempo para postergação da imunização com a vacina contra a Hepatite $B$, permitida para bebês nascidos de mães cujo exame foi negativo para a doença (15). Assim, a primeira dose da vacina pode ser administrada posteriormente, entre dois a seis meses de vida. Bebês 
prematuros com peso inferior a 2000 g, não devem receber imunização contra a Hepatite $B$, ao menos que a mãe tenha resultado positivo para o exame (16). A recomendação é para que bebes prematuros de mães saudáveis sejam vacinados apenas ao atingirem a idade corrigida para o termo (40 semanas) e o peso de pelo menos $2500 \mathrm{~g}(15)$.

Porém, as orientações para populações onde o exame não é rotineiro no prénatal, é de que todas as crianças sejam vacinadas ao nascer (15). O Manual de Normas e Procedimentos para Vacinação no Brasil (2014)(1) não faz referência à imunização para Hepatite $B$ de recém-nascidos prematuros. O calendário de vacinação do prematuro da Sociedade Brasileira de Imunizações (SBIm) (100), por sua vez, recomenda que a primeira dose da vacina seja administrada nas primeiras doze horas de vida.

O Manual dos Centros de Referência de Imunobiológicos Especiais (CRIE) (2001), do Ministério da Saúde, informa que: "fazer sorologia materna sistemática para o vírus da hepatite $B$ torna-se dispensável, uma vez que se vacinem de maneira rotineira e adequada todos os recém-nascidos. Tem a utilidade de chamar a atenção para os recém-nascidos que, sem profilaxia, teriam altíssimo risco de adquirir a infecção no período perinatal" (101, p. 60). Convém esclarecer que crianças prematuras são aquelas nascidas antes de 37 semanas de gestação ou com peso inferior a $2500 \mathrm{~g}$ (102). O Manual CRIE (2014) informa que se a situação da sorologia materna para a Hepatite B é desconhecida, deve-se proceder a imunização imediatamente ao recém-nascido, independente de peso ou idade gestacional (102).

Cabe registrar que a Portaria $n^{\circ} 828$, de 5 de Julho de 2016, do MS, incluiu o procedimento de teste rápido para detecção de infecção por Hepatite B na tabela de procedimentos, medicamentos, órteses/próteses e materiais do SUS (103). A recomendação do Manual Técnico: Pré-natal e Puerpério Atenção Qualificada e Humanizada (2006), do MS, é que a triagem para Hepatite b seja realizada sempre que for possível (104). Entretanto, atualmente o exame para Hepatite B (HbsAg) consta da lista de exames recomendados a serem realizados no pré-natal (105).

O esquema básico de vacinações obrigatórias na rede pública de saúde inclui vacinações em quatro doses, sendo que a primeira dose de Hepatite B monovalente ao nascimento, deve ser realizada o mais precocemente possível, nas primeiras 24 
horas, e preferencialmente nas primeiras 12 horas após o nascimento. As demais doses são administradas na forma de vacina Pentavalente (DTP, Hib, HB) aos 2, 4 e 6 meses (102). O valor do exame na tabela do SUS para pesquisa de antígeno de superfície do vírus da hepatite $B(H B S A G)$ é de $R \$ 18,55$ (dezoito reais e cinquenta e cinco centavos) (106). De acordo com o calendário de vacinação da Sociedade Brasileira de Pediatria (SBP) (2016):

\begin{abstract}
A primeira dose da vacina Hepatite B deve ser idealmente aplicada nas primeiras 12 horas de vida. A segunda dose está indicada com 1 ou 2 meses de idade e a terceira dose é realizada aos 6 meses. A segunda dose está indicada com 1 ou 2 meses de idade e a terceira dose é realizada aos 6 meses. Desde 2012 no Programa Nacional de Imunizações (PNI), a vacina combinada DTP/Hib/HB (denominada pelo Ministério da Saúde de Penta) foi incorporada aos 2, 4 e 6 meses de vida. Dessa forma, os lactentes que fizerem uso desta vacina recebem quatro doses da vacina Hepatite B. Aqueles que forem vacinados em clínicas privadas podem manter o esquema de três doses, primeira ao nascimento e segunda e terceira dose aos 2 e 6 meses de idade. Nestas duas doses, pode- se utilizar vacinas combinadas acelulares - DTPa/IPV/Hib/HB. Crianças com peso de nascimento igual ou inferior a $2 \mathrm{~kg}$ ou idade gestacional < 33 semanas devem receber, além da dose de vacina ao nascer, mais três doses da vacina (total de 4 doses, 0, 2, 4 e 6 meses). Crianças maiores de 6 meses e adolescentes não vacinados devem receber 3 doses da vacina no esquema 0, 1 e 6 meses; 0,2 e 6 meses; ou 0, 2 e 4 meses. A vacina combinada Hepatite A+B (apresentação adulto) pode ser utilizada na primovacinação de crianças de 1 a 15 anos de idade, em 2 doses com intervalo de seis meses. Acima de 16 anos o esquema deve ser com três doses (0, 1 e 6 meses). Em circunstâncias excepcionais, em que não exista tempo suficiente para completar o esquema de vacinação padrão de 0,1 e 6 meses, pode ser utilizado um esquema de três doses aos 0,7 e 21 dias. Nestes casos uma quarta dose deverá ser feita, 12 meses após a primeira dose, para garantir a indução de imunidade em longo prazo (107, p. 2 notas explicativas).
\end{abstract}

Verifica-se, portanto, que o documento da SBP confirma a vacinação de recémnascidos prematuros nas primeiras 12 horas de vida. O padrão para os bebês vacinados em clínicas privadas reduz de 4 para 3 doses, sendo a primeira dose ao nascimento, a segunda aos 2 meses e a terceira dose aos 6 meses. Com isso, além da diminuição do número de doses, nas clínicas privadas a vacina administrada não contém o conservante Timerosal, uma vez que é acondicionada em frasco monodose. 
6.3 ANÁLISE DESCRITIVA DO DOCUMENTO THE SAFETY OF THIOMERSAL, DA OMS (2012).

Elaborado pelo Comitê Consultivo Global sobre segurança em vacinas (Global Advisory Committee on Vaccine Safety), estabelecido pela Organização Mundial de Saúde, o documento remete à Declaração Conjunta emitida em 1999, e abordada no tópico 6.2. Aponta que, baseado no Princípio da Precaução, autoridades norte-americanas tomaram a decisão de remover o Timerosal das vacinas infantis, considerando o cálculo de que o calendário de imunização da primeira infância apontava para doses cumulativas de mercúrio além dos níveis de proteção estabelecidos pela Agência de Proteção Ambiental Norte-americana, considerando o padrão de segurança para exposição ao metilmercúrio.

De acordo com o documento, o Comitê revisou estudos farmacocinéticos e epidemiológicos a respeito do Timerosal entre os anos 2002 e 2008, tendo concluído que a toxicidade em animais ou humanos, incluindo bebês prematuros e de baixo peso, apontam que os níveis de etilmercúrio no sangue e no cérebro das doses cumulativas de vacinas não atingem níveis tóxicos, sendo biologicamente implausível a relação entre Timerosal em vacinas e neurotoxicidade.

A OMS reafirmou a segurança no uso do Timerosal como conservante em vacinas e defende sua utilização, pois, segundo o documento, a utilização do componente permite que pessoas em todo o mundo tenham acesso a vacinas que são capazes de salvar vidas, e enfatizam que não existe alternativa mais segura e eficaz quanto o Timerosal para a conservação de muitas vacinas. Assim, o documento tem sido largamente utilizado nos países periféricos, para confirmar a segurança na utilização do Timerosal como conservante de vacinas, bem como uma solução de baixo custo e viável para tais países. 


\section{DISCUSSÃO}

Feitosa e Nascimento (2015) correlacionam a gênese da Bioética de Intervenção às lutas no âmbito da saúde pública em torno da Reforma Sanitária Brasileira, através da participação política e intelectual do principal expoente da teoria, Volnei Garrafa (108), marcada pela publicação do livro "Contra o Monopólio da Saúde", em 1981 (109). Publicações realizadas entre os anos de 1995 e 1999, definem o período considerado pelos autores como a etapa gestacional da $\mathrm{BI}$, de forte vinculação teórico-política à saúde pública (108). Os autores caracterizam a BI como uma "proposta de libertação, que considera as relações injustas estabelecidas entre o hemisfério Norte e o Sul, evidenciadas pelas desigualdades sociais que distinguem os países centrais dos países periféricos" (108, p.280).

As publicações "Bioética, poder e injustiça: por uma ética de intervenção" (2002) (110) e Intervention bioethics: a proposal for pheripheral countries in a context of power and injustice (2003) (19) são consideradas por Martorell (2015) como textos iniciais de fundamentação teórica da BI no âmbito acadêmico (111) e apontam para a necessidade de que a bioética dos países periféricos atente, em especial, para as questões relativas aos problemas éticos persistentes, sobretudo, através da politização dos conflitos morais (108).

A pergunta central deste trabalho parte de uma questão recorrente no cotidiano das populações dos países periféricos: é moralmente aceitável que crianças sejam expostas ao mercúrio, utilizado como conservante de vacinas, substância potencialmente neurotóxica, durante o período intrauterino, nas primeiras doze horas de vida e, repetidas vezes, ao longo dos seis primeiros meses de vida, enquanto crianças de países centrais são poupadas de tal exposição há, pelo menos, uma década?! A partir desse questionamento, constatou-se a intrínseca similaridade entre o duplo padrão de segurança em vacinas pediátricas e o duplo padrão em pesquisas, este chancelado pelas alterações recentes na Declaração de Helsinki.

A primeira versão da Declaração de Helsinki foi homologada em 1964, e em 2013 foi realizada a última, de sete revisões. A Declaração alcançou elevada 
aceitação mundial como referência para diretrizes éticas nas investigações com seres humanos. Entretanto, a partir de 2008, alterações estruturais foram incorporadas ao texto, e, por conseguinte, muitos países e entidades passaram a não mais usá-la como referência técnica e moral para pesquisas envolvendo seres humanos (112). Garrafa (2005) avalia que a Declaração Universal sobre Bioética e Direitos Humanos representou um marco para o avanço nas discussões de questões referentes à saúde pública e inclusão social (25). Para o autor, a inclusão de um tópico no preâmbulo da DUBDH poderia combater práticas de duplo padrão em pesquisa envolvendo seres humanos: "Considerando que todos os seres humanos, sem distinção, devem se beneficiar dos mesmos elevados padrões éticos na medicina e nas pesquisas em ciências da vida" $(24$, p.4).

Assim, a Declaração de Córdoba, elaborada no Congresso de Bioética organizado pela Rede Bioética Latino-americana e do Caribe (Redbioética), em 2008, recomendou que países, governos e instituições façam uso da DUBDH como referência, em detrimento da Declaração de Helsinki, como repulsa às alterações realizadas durante a $59^{\circ}$ Assembleia da Associação Médica Mundial, em Seul, Coreia do Sul, naquele mesmo ano (113). Tais alterações ocorreram como resposta à pressão exercida por países ricos, como os Estados Unidos, e por empresas farmacêuticas, para assegurar seus interesses econômicos (112). Garrafa (2015) afirma que o documento deixou de servir como um parâmetro técnico-científico para transformar-se em um instrumento político internacional, com vistas à obtenção de lucro e vantagens (112).

As alterações mais importantes na Declaração de Helsinki se referem ao enfraquecimento das regras sobre o uso do placebo, possibilitando a ocorrência de duplo padrão de pesquisas realizadas com protocolos diferentes em países ricos (centrais) e pobres (periféricos). Outro aspecto relevante diz respeito às obrigações dos patrocinadores com os sujeitos de pesquisa ao término dos ensaios clínicos (112). Garrafa (2015) ainda questiona se é justificável que se apliquem padrões éticos diferenciados para protocolos de pesquisa em razão dos diferentes níveis socioeconômicos dos países (112).

Traçando um paralelo entre o duplo padrão em pesquisas e o duplo padrão de segurança em vacinação entre países centrais e periféricos, este acontece à medida 
que países centrais iniciaram a retirada do Timerosal das vacinas pediátricas em resposta ao alerta emitido em 1999 pela American Academy of Pediatrics e o United States Public Health Service, e reiterado no ano seguinte através da publicação: Joint Statement Concerning Removal of Thimerosal from Vaccines (2000). Considerando o Princípio da Precaução, atentou-se para a hipótese de que crianças podem ser submetidas a doses cumulativas de mercúrio ao cumprir o calendário de vacinação nos seis primeiros meses de vida, excedendo padrões de segurança para exposição ao mercúrio.

\subsection{O MERCADO DE VACINAS}

O ponto central de discussão sobre a utilização do Timerosal como conservante de vacinas infantis gira em torno de questões econômicas, pois é interessante para o mercado a manutenção do baixo custo de produção de vacinas multidoses conservadas em mercúrio, ainda que o Princípio da Precaução não seja observado. Ademais, a atenção dos grandes fabricantes tem se voltado para a inserção de novas vacinas, elaboradas com alta tecnologia e elevado valor agregado (50). É relevante sublinhar, em relação ao mercado de vacinas, a atuação do GAVI, entidade composta pelos setores público e privado e destinado a promover a inclusão de novas vacinas no calendário de vacinação dos países periféricos, através do financiamento temporário dessas vacinas $(86,87)$.

Enquanto o mundo se mobiliza para a diminuição ou retirada do mercúrio em processos e uso em diversos setores, inclusive na área da saúde, a manutenção do uso do Timerosal como conservante de vacinas infantis provoca uma série de inquietações, pois a continuidade do seu uso é considerada injustificada, uma vez que existem opções de conservantes não mercuriais viáveis economicamente e menos sensibilizantes que o Timerosal (114), ou ainda quando pode-se fazer uso de vacinas em frascos monodose ou em seringas preenchidas.

A revisão de literatura permitiu verificar que o uso de vacina em frasco 
monodose é vantajoso frente a utilização das vacinas multidoses. Um dos elementos fundamentais a ser considerado é o desperdício em função de fatores como limitação da vida útil da vacina após a abertura do frasco e contaminação, bem como a não utilização de todas as doses, em caso de reduzido número de pacientes $(48,49)$. Outro achado relevante foi a constatação de que na tabela de preços máximos de medicamentos para compras públicas, o valor da dose de vacina para Hepatite $B$, fornecida pelo laboratório GSK, em seringa preenchida monodose tem o custo máximo de $\mathrm{R} \$ 30,41$ por dose, sendo portanto, inferior ao valor por dose em frascos multidoses pago pelo Governo, uma vez que o Instituto Butantan fornece a vacina Hepatite B em frascos multidoses para as unidades de vacinação no SUS ao valor máximo de $\mathrm{R} \$ 32,56$ por dose (95). Assim, é injustificado dizer que no Brasil, o uso de VCT se deve a questões econômicas, de menor preço.

Enquanto o uso de VCT é uma realidade no SUS, a rede particular de clínicas de imunologia fornece apenas vacinas em frasco monodose, sem o conservante. $\mathrm{Na}$ rede privada, a vacina Hepatite $B$ pode custar quatro vezes mais que o valor pago pelo governo aos fabricantes de vacinas, porém, as clínicas estão lotadas de pessoas que desejam pagar para ter segurança em saúde. Essa prática acontece tanto em clínicas de Brasília, quanto no interior do Nordeste, em cidades como Teresina e Parnaíba, no Piauí. Assim, verifica-se que as assimetrias no mercado de vacinas não ocorrem apenas entre países periféricos e centrais, mas revela-se como uma prática que remete ao conceito de saúde como um bem e está baseada na capacidade de pagar, delineada por Beauchamp e Childress (58).

Em consonância com as publicações da American Academy of Pediatrics e do United States Public Health Service, em 2004, o Institute of Medicine, que desde 1970 atua como conselheiro para o Governo Federal em questões relativas à saúde pública, emitiu documento relatando que os EUA retiraram o Timerosal das vacinas por medidas de precaução e advertiam que cada país deveria fazer suas próprias avaliações de riscos e benefícios, podendo alcançar conclusões diferentes sobre a eliminação do Timerosal em vacinas infantis e que as conclusões não deveriam incluir o autismo como um potencial de risco (2).

No Brasil, a Agência Nacional de Vigilância Sanitária (ANVISA), por meio da Resolução Federal RE $n^{\circ} 528$ de 2001, considerou a relação risco benefício 
desfavorável para a utilização de derivados mercuriais em antissépticos tópicos, bem como a proibição de sua utilização em medicamentos (art. 1) e manipulação em compostos magistrais (art. 4). A Resolução, porém, manteve a permissão para a continuidade no uso do mercúrio como conservante de vacinas (art. 5) (115).

\subsection{OS QUATRO “PÊS” DA BIOÉTICA DE INTERVENÇÃO}

A vigilância sanitária, conforme a Lei $n^{\circ}$ 8080/90, é responsável por desenvolver um "conjunto de ações capaz de eliminar, diminuir ou prevenir riscos à saúde e de intervir nos problemas sanitários decorrentes do meio ambiente, da produção e circulação de bens e da prestação de serviços de interesse da saúde" $(116$, p.2). Entretanto, como visto anteriormente, a ANVISA manteve a permissão para que o mercúrio continue sendo utilizado como conservante de vacinas no Brasil. Martorell (2015) entende que a Bioética de Intervenção é "uma ferramenta possível para a avaliação de conflitos morais e de proposição de suas resoluções" (111, p.104), capaz de exercer influência em instituições como a ANVISA e o Ministério da Saúde, que são responsáveis por executar ações concretas na área da saúde.

É atribuição da Agência Nacional de Vigilância Sanitária promover a proteção da saúde da população, através do controle sanitário da produção, comercialização de produtos e serviços submetidos à vigilância sanitária (117) Nesse sentido, Leite et al (2008) invocam a necessidade de que parâmetros éticos, indispensáveis ao desenvolvimento de práticas responsáveis, deem sustentabilidade às ações a serem executadas pela ANVISA, por meio de conceitos como os 4 "Pês" (precaução, proteção, prudência e prevenção) (21), utilizados na Bioética de Intervenção, e invocados aqui para a observância dos padrões éticos no manejo da vacinação infantil. Tais ferramentas podem ser utilizadas em conflitos éticos e morais na saúde pública, e possuem a capacidade didática de desnudar processos iníquos no que se refere ao manejo em saúde (118).

Leite et al (2008) destacam a responsabilidade como um ponto de intersecção 
entre a precaução e a proteção e evidenciam que as concessões de permissões ou penalidades no âmbito da saúde pública deveriam possuir uma base epistemológica pertinente, a exemplo dos 4Ps (118):

\begin{abstract}
Dentro da Bioética de intervenção, os "Quatro Pês" são referenciais teóricos e práticos referidos frente a novas tecnologias de serviços e produtos para a saúde, bem como os procedimentos por eles utilizados. A prudência e a precaução são categorias buscadas no momento de desconhecimento dessas novas tecnologias. A proteção e a prevenção, muito conhecidas da Vigilância Sanitária, são referências utilizadas para evitar possíveis danos e iatrogenias advindos do uso dessas tecnologias, uma vez que a população doente que necessita das mesmas é vulnerável e suscetível, ao mesmo tempo, aos possíveis riscos associados (118, p. 186).
\end{abstract}

Cruz e Trindade (2006) descrevem o comprometimento da $\mathrm{BI}$ com os mais vulneráveis e com o equilíbrio do meio ambiente no séc. XXI ao destacar os 4 Pês como fundamento essencial da sua teoria (119). Aqui fazemos referência mais enfática sobre a prevenção de danos e iatrogenias e a precaução frente ao desconhecido. Em sua obra: Nemessis da Medicina: la expropiacion de la salud (1975), Ivan Illich descreve o termo iatrogenia como uma nova epidemia de enfermidades produzidas por médicos, do grego iatrós ou médicos e génesis: origem, causa. Assim, as iatrogenias compreendem os estados clínicos nos quais os agentes causadores dos males são os medicamentos, os médicos ou hospitais (120). Para Berlinguer "um dos privilégios éticos da prevenção está na sua virtude antecipatória, na capacidade de intervir com a finalidade de evitar um dano e possui potencial igualitário" (121).

O Princípio da Precaução surgiu em referência às questões ambientais na década de 1970, mas na década de 1990 começou a ser utilizado extensivamente no campo da saúde pública. O princípio é invocado sempre que existe incerteza, em meio a plausibilidade científica de ocorrer um dano: "dano moralmente inaceitável, que é cientificamente plausível, mas incerto" (66, p. 14) A aplicabilidade do PP pode ser considerada nas discussões políticas e tomadas de decisão, sobretudo, no que concerne à toxicidade de produtos químicos cujas informações muitas vezes são limitadas, a exemplo do baixo nível de informação científica definitiva sobre a 
toxicidade do etilmercúrio em vacinas (13).

Atentos ao Princípio da Precaução, e seguindo o padrão de países centrais, legisladores chilenos aprovaram o banimento do Timerosal como conservante de vacinas, entretanto, o poder executivo daquele país, vetou a iniciativa (122). O Comitê consultivo de imunizações, da Sociedade Chilena de Infectologia, emitiu na ocasião uma declaração reafirmando que "não há evidência sólida de eventos adversos associados ao uso de vacinas contendo Timerosal em bebês e crianças" (123). A publicação da Global Advisory on Vaccine Safety, comitê da OMS para temas relacionados a segurança em vacinas, foi decisiva para influenciar especialistas e representantes do Ministério da saúde do Chile para a manutenção do uso de VCT (124).

Sabe-se que processo de vacinação não é completamente seguro e eficaz, e por isso, frente à possibilidade de ocorrer efeitos e reações adversas individuais, de acordo com a loteria natural e social, alguns sofrerão danos, em detrimento do benefício da coletividade $(20,125)$. Embora não seja objeto de estudo deste trabalho, cabe evidenciar que, atualmente, aproximadamente dezenove países possuem programas de compensação às reações adversas causadas por vacinas, e nenhum desses países está localizado no hemisfério sul $(20,125)$. Para Lessa e Schramm (2015), as políticas públicas em saúde deveriam graduar os níveis de vulnerabilidade, de forma que se pudesse alcançar a equidade e promover a justiça social (20).

\subsection{DECLARAÇÃO UNIVERSAL SOBRE BIOÉTICA E DIREITOS HUMANOS}

O cerne da DUBDH está fundamentado sob 15 princípios, que são os artigos de 3 a 17. Faz-se necessário compreender que a Declaração foi construída de acordo com um nível crescente de objetos morais, que se inicia com o ser humano em sua individualidade (dignidade humana, benefício e dano e autonomia), seguido por outros seres humanos (consentimento, privacidade e igualdade), a vida em 
sociedade (respeito pela diversidade cultural) a humanidade em seu sentido amplo (solidariedade, responsabilidade social e partilha de benefícios), e por fim, todos os seres vivos e o meio ambiente (proteção das futuras gerações, do meio ambiente da biosfera e da diversidade) (126).

A DUBDH aborda as questões éticas que envolvem a medicina, as ciências da vida e tecnologias associadas no que se refere à sua aplicação em seres humanos, observando os aspectos sociais, legais e ambientais (126), possuindo a noção de dignidade humana como um fio condutor o longo do texto, assim, todos os princípios da Declaração derivam da dignidade inerente ao ser humano (127). Neste trabalho foram escolhidos três princípios da DUBDH que se relacionam às questões sobre o duplo padrão de segurança em vacinas pediátricas, a saber: art. $4^{\circ}-$ Benefício e Dano; art. $8^{\circ}$ - Respeito pela vulnerabilidade humana e integridade individual; e art. $10^{\circ}$ - Igualdade, justiça e equidade.

\subsubsection{Benefício e Dano}

O Princípio do Benefício e Dano está intrinsecamente relacionado aos 4 "Pês" descritos na BI. Segundo Pellegrino (2009) (128), o Princípio do Benefício e Dano, na DUBDH, seguiu uma lógica de construção sequenciada, a partir do art. $3^{\circ}$ da declaração, que trata da dignidade humana e direitos humanos, não voltados exclusivamente para a coletividade, mas valorizando a dignidade inerente ao ser humano e a subjetividade dos indivíduos: "a) A dignidade humana, os direitos humanos e as liberdades fundamentais devem ser respeitados em sua totalidade". De acordo com este artigo "os interesses e o bem-estar do indivíduo são prioritários frente o interesse da ciência ou da sociedade" (24, art. 3). Desta forma, cabe evidenciar o fato de que a maximização de benefícios e a minimização de danos a pacientes e sujeitos de pesquisa deve ter prioridade frente ao interesse da coletividade e da ciência. Observe-se: 
Os benefícios diretos e indiretos a pacientes, sujeitos de pesquisa e outros indivíduos afetados devem ser maximizados e qualquer dano possível a tais indivíduos deve ser minimizado, quando se trate da aplicação e do avanço do conhecimento científico, das práticas médicas e tecnologias associadas. (24, art. 4)

Para Pellegrino a dignidade inerente ao ser humano gera a obrigação moral e universal de se fazer o bem e evitar danos a outros seres humanos. $O$ autor entende que este princípio se aproxima do Princípio da Beneficência e Não Maleficência, difundidos no Principialismo de B\&C. Descreve ainda que Frankena entendia os Princípios da Não Maleficência e da Beneficência como um único princípio, passível de ser decomposto em quatro obrigações morais, organizadas de forma hierárquica, no qual o nível mais baixo seria a própria não maleficência, ou seja, não causar dano. O próximo nível, de forma ascendente seria remover o dano, seguido pelo dever de prevenir o dano e finalmente, promover o bem $(128,58,75)$.

Esta discussão não advoga pela abstenção da vacinação infantil, mas faz uma análise do que é moral e eticamente questionável, através da observância da necessidade de prevenir danos potenciais a uma população vulnerável, considerando o Princípio da Precaução, tal qual definido pelo órgão consultivo da UNESCO, como dano moralmente inaceitável, plausível cientificamente, porém incerto (66), bem como os quatro "Pês" da Bl e o art. 4 da DUBDH.

Assim, entende-se que o duplo padrão de vacinação infantil é direcionado e subserviente aos interesses do mercado, no qual o grupo composto por fetos, recémnascidos, prematuros e bebês, é submetido a doses repetitivas de mercúrio nos estágios iniciais da vida, de maneira intencional. A chancela da OMS deve ser questionada, pois serve como fundamento para que os governos mantenham o uso de VCT, ao advogar pela continuidade na utilização do mercúrio em vacinas, por uma questão meramente econômica. 


\subsubsection{Respeito pela Vulnerabilidade Humana e Integridade Individual}

A BI possui uma aliança histórica com o lado mais frágil da sociedade, sobretudo com aqueles que se encontram em situação de maior vulnerabilidade. E por isso, em consonância com a DUBDH, entendemos que fetos, prematuros e recém-nascidos constituem um grupo com vulnerabilidade específica, e que, por isso, deveria ser poupado de qualquer situação de risco potencialmente danosa capaz de ferir sua integridade individual, agravando a condição de vulnerabilidade. O mercúrio em vacinas pediátricas é um agravante aos riscos a que são submetidas grande parte das crianças nos países periféricos, que convivem exaustivamente com situações de falta de saneamento básico, com verdadeiros esgotos a céu aberto, falta de segurança alimentar através do uso de agrotóxicos banidos nos países centrais, desnutrição, descarte indevido de lixo urbano, assistência médica precarizada.

O Artigo $8^{\circ}$ da DUBDH versa sobre o Respeito pela Vulnerabilidade Humana e pela Integridade Individual e não fazia parte dos textos preliminares de esboço da Declaração, tendo sido proposto e aceito durante a segunda e última reunião intergovernamental de especialistas, em junho de 2005 (129). Assim:

A vulnerabilidade humana deve ser levada em consideração na aplicação e no avanço do conhecimento científico, das práticas médicas e de tecnologias associadas. Indivíduos e grupos de vulnerabilidade específica devem ser protegidos e a integridade individual deve ser respeitada (24, art. 8).

Segundo Patrão Neves (2006), vulnerabilidade deriva do latim vulnus, que significa "ferida", podendo ser entendida como capacidade de ser ferido. De acordo com a autora, o Belmont Report foi o primeiro documento bioético que aponta para uma significação ética específica da noção de vulnerabilidade de um indivíduo ou grupo de pessoas que possam ser expostas ao risco de agravos no âmbito da pesquisa biomédica. $O$ termo foi inserido pela primeira vez na Declaração de Helsinki na sua revisão de 1996 (130).

Foi apenas a partir da $6^{a}$ edição que a obra de Beauchamp e Childress 
"Principles of biomedical ethics", recebeu um item específico sobre vulnerabilidade com o título "vulnerabilidade e exploração", que e na $7^{\text {a }}$ edição passou a ser "vulnerabilidade, exploração e discriminação na pesquisa" (57). Garrafa aborda o conceito de vulnerabilidade social que está relacionado ao risco de ocorrência de evento potencialmente danoso e diz respeito a um indivíduo, comunidade ou camada social, graças a fatores socioeconômicos e/ou culturais. Situações geradoras da vulnerabilidade social podem incluir disparidades socioeconômicas da população, baixo nível de instrução educacional, baixa capacidade de pesquisas no país, dentre outros (112).

O estudo crítico sobre o Princípio de Benefício e Dano de Paranhos et al (2015) destaca o aspecto da vulnerabilidade a que as populações dos países mais pobres estão sujeitas:

Pode-se constatar, pelo levantamento da literatura, que ainda restam muitas situações em que os mais vulneráveis estão sob risco. Não por acaso, tais situações acontecem justamente nos países mais pobres, onde, então, se procura relativizar sua vulnerabilidade, intensificando assim os benefícios que lhes são devidos e os riscos de danos a que estão potencialmente expostos (131, p.18).

O termo integridade, por sua vez deriva do latim tangere, cujo significado remete a intocado, completo.(132) O Pacto de São José da Costa Rica, de 1969, que versa sobre Direitos humanos, aborda em seu art. $5^{\circ}$ o Direito à Integridade Pessoal, através do qual, "toda pessoa tem o direito de que se respeito sua integridade física, psíquica e moral” (133). As históricas atrocidades praticadas nos campos de concentração por médicos nazistas marcaram a violação de direitos básicos, como a integridade física e psíquica, em nome do desenvolvimento científico e de pesquisas médicas. Após a Segunda Guerra Mundial e a constituição do Tribunal de Nuremberg (1947), verificou-se a inexistência de normas regulamentadoras de práticas de pesquisa envolvendo seres humanos (134).

Assim, o Código de Nuremberg (1947) elencou dez princípios norteadores para as pesquisas envolvendo seres humanos, dos quais pelo menos cinco se referem à minimização de riscos e danos aos sujeitos de pesquisa. O sétimo princípio afirma que: "devem ser tomados cuidados especiais para proteger o 
participante do experimento de qualquer possibilidade de dano, invalidez ou morte, mesmo que remota" (135). Oliveira (2009) considera a criação desse documento internacional um fato essencialmente bioético (136).

No contexto deste trabalho, os bebês prematuros representam uma parcela da população infantil essencialmente vulnerável à exposição do Timerosal em vacinas, especialmente à vacina Hepatite $B$, que é administrada nas primeiras doze horas de vida, especialmente em hospitais da rede pública de saúde. Pichichero et al (2002) concluíram que os níveis de mercúrio em crianças nascidas a termo e vacinadas com VCT são inferiores aos índices potencialmente tóxicos, porém, alertam para o fato de que bebês prematuros com extremo baixo peso ao nascer não deveriam ser vacinados nas primeiras horas de vida (36).

Nos países centrais, onde o exame para detecção da Hepatite B é realizado durante o pré-natal, o manejo para administração da vacina é diferente daquele utilizado nos países periféricos, onde todos os recém-nascidos devem ser indiscriminadamente vacinados, independente do peso ou idade gestacional. A Academia Americana de Pediatria informa que a vacina pode ser postergada de 2 a 6 meses após o nascimento, em bebês cujas mães tiveram o exame negativo para a Hepatite B. Ademais, no Brasil, o exame para pesquisa da Hepatite B faz parte dos exames essenciais que deveriam ser realizados durante o pré-natal, e seu custo para o SUS $(R \$ 18,55)$ é inferior ao valor da dose da vacina (R\$32,56) (106). Com isso, acreditamos que bebês prematuros nos países periféricos poderiam ser poupados de tal exposição no momento crítico, que são as primeiras horas de vida.

A literatura aponta diversas situações nas quais pessoas vulneráveis estão submetidas a algum risco. Tais situações são cotidianamente vivenciadas nos países do hemisfério sul, leia-se países periféricos, onde as pessoas estão potencialmente expostas a sofrerem danos (131). Tickner e Hoppin (2000) não tratam especificamente do Timerosal em vacinas, mas abordam a vulnerabilidade de crianças à exposição de substâncias tóxicas e afirmam que o desenvolvimento de algumas crianças é afetado desde a vida intrauterina por exposições ambientais. Durante as fases de crescimento, processos de desenvolvimento podem ser interrompidos facilmente, ocasionando lacunas de vulnerabilidade, nos quais curtos períodos de exposição a tóxicos podem ocasionar danos irreversíveis ao longo da 
vida. Segundo os autores, a incerteza quanto à magnitude e tipo de dano, são razões para que medidas de precaução sejam tomadas, sobretudo, ao se tratar de exposição de substâncias potencialmente danosas a fetos, lactentes e crianças (137).

A avaliação de risco é um processo que envolve a identificação de agravos por meio da existência de uma relação causal, através de um sistema de avaliação baseado em dados científicos, com o objetivo de proteger a saúde pública e o ambiente, mas que, ao mesmo tempo, permite o acesso a produtos potencialmente danosos. O processo de avaliação de risco não tem obtido êxito nos países periféricos, onde empresas comerciais privadas conseguem influenciar e manipular o mercado. Assim, as avaliações de risco apenas legitimam o uso de substâncias danosas em face da desinformação da população sobre os possíveis danos advindos de produtos tóxicos a que são submetidos (138).

Para Quijano (2000), embora exista o discurso de proteção à saúde e ao meio ambiente, os interesses de fins lucrativos das grandes corporações de produtos químicos se sobrepõem, possibilitando a produção, comercialização e utilização de produtos tóxicos. Segundo esse autor, apesar da evidência de danos para o ambiente e a saúde humana, essas empresas encontram aprovação até mesmo de organismos internacionais como a OMS e Organização das Nações Unidas para Agricultura e Alimentação (FAO), com base nas próprias avaliações de risco, apesar da evidência de danos para o ambiente e a saúde humana, incluindo a manipulação de dados dirigida para o mercado e resultados com informações distorcidas (138).

\subsubsection{Igualdade, Justiça e Equidade}

A Bioética de Intervenção aborda os conceitos de equidade, justiça e igualdade desde o seu nascimento como teoria voltada para a defesa de interesses e direitos das populações excluídas econômica e socialmente ao analisar dilemas frequentes como autonomia versus justiça/equidade; benefícios individuais versus coletivos; 
individualismo versus solidariedade, dentre outros. A inserção dos princípios da equidade e justiça na DUBDH permitiram uma maior visibilidade para o tema da justiça social no âmbito da bioética. Assim, o caráter social da Bioética alcançou maior amplitude, para além das questões estritamente biomédicas e biotecnológicas.(139)

Desde o preâmbulo, a DUBDH expõe a necessidade de um enfoque para que o progresso da ciência e da tecnologia promova as questões de justiça e equidade. $\mathrm{O}$ art. 10 da DUBDH trata da Igualdade, Justiça e Equidade, e afirma que: "a igualdade fundamental entre todos os seres humanos em termos de dignidade e de direitos deve ser respeitada de modo que todos sejam tratados de forma justa e equitativa" (24).

Para Corgozinho e Oliveira (2016), a equidade em saúde deve ser capaz de promover o aumento de oportunidades, especialmente para as populações mais vulneráveis (139). Busca-se através da equidade em saúde que singularidades e necessidades particulares sejam observadas, considerando fatores determinantes de saúde, como acesso à água potável, saneamento básico e segurança alimentar (140). $\mathrm{A} \mathrm{BI}$ reconhece a equidade como sendo diferente da igualdade. Para Garrafa e Porto (2003), a equidade é o ponto de partida para a igualdade, podendo ser alcançada através do reconhecimento das diferenças e necessidades diversas dos sujeitos sociais. A igualdade, por sua vez, representa o ponto de chegada da justiça social (110).

A Bioética de Intervenção explicita:

\begin{abstract}
A igualdade como o ponto de chegada da justiça social, referencial dos direitos humanos mais elementares, cujo objetivo futuro é o reconhecimento da cidadania. A busca da equidade, o reconhecimento das necessidades diversas em sujeitos também diferentes para atingir objetivos iguais são um dos caminhos da ética prática diante da necessidade de expandir o acesso aos direitos humanos universais" (110, p. 38).
\end{abstract}

No âmbito da saúde pública a equidade expressa que as diferenças individuais devem resultar em tratamento diferenciado, de acordo com vulnerabilidades próprias, (139) ou seja, a diferença entre as pessoas, bem como suas condições sociais e 
sanitárias devem ser consideradas (25):

Nos países latino-americanos, de modo geral, e no Brasil, especificamente, o tema da justiça sanitária faz parte da agenda bioética. As imensas desigualdades no acesso aos recursos - a tudo que caracteriza a qualidade de vida - tornam esse tema efetivamente orgânico quando se pretende aplicar a ética para garantir a dignidade da vida humana $(25$, p. 123).

O Principialismo de Beauchamp e Childress, ancorado no princípio da autonomia, apresenta limitações para explicar as demandas persistentes dos países periféricos. De acordo com o Princípio da Justiça, na obra de B\&C, a saúde não representa um direito, e sim um "bem", onde as leis de livre mercado são norteadoras para garantir o acesso aos serviços médicos, e por conseguinte, distribuída a cada um conforme a capacidade de pagar (57). Repetidamente, os autores tentam preencher as lacunas sobre conceitos relativos à justiça através do uso de exemplos que se aproximam do conceito de beneficência ou autonomia.

A discussão de B\&C não se concentra na garantia de direitos, mas na melhor relação custo-benefício, assim: "Numa economia de mercado, todos os tipos de bens, incluindo a assistência médica, estão, em alguma medida, racionados pela capacidade de pagar" (58, p. 396). O Relatório Belmont elencou 5 características básicas ao princípio da justiça: (1) para cada pessoa uma parte igual, (2) a cada pessoa de acordo com a necessidade individual, (3) a cada pessoa de acordo com o esforço individual, (4) a cada pessoa de acordo com a contribuição social e (5) A cada pessoa de acordo com o mérito (56).

Beuchamp e Childress acrescentaram uma característica ao princípio da justiça: a cada um de acordo com as trocas de livre mercado. Os autores descreveram seis teorias da justiça, a saber: utilitaristas, liberais, comunitaristas, igualitárias, das capacidades e do bem-estar (18). O pensamento ético liberal advoga em favor das leis de livre mercado como garantidoras de uma sociedade justa, assim, as desigualdades sociais são justificáveis, pois o princípio da liberdade individual é resguardado.

Em contrapartida, sob a perspectiva das teorias éticas voltadas para a equidade, as políticas públicas são responsáveis por garantir a justiça distributiva, 
reduzindo os efeitos da loteria natural e social (141). Fortes (2010) questionou em "A equidade no sistema de saúde na visão de bioeticistas brasileiros" o que seria um sistema de saúde fundado no princípio da equidade?". A resposta mais prevalente foi que o SUS deveria tratar desigualmente os desiguais conforme suas necessidades particulares (142). Para Kalckmann et al (2007) "os serviços de saúde devem oferecer tratamentos diferenciados e específicos para os desiguais, visando reduzir diferenças de vulnerabilidade das populações" (143).

Nesse sentido, King et al (2013) defendem que não existe injustiça no uso de um padrão diferenciado de vacinas administradas a crianças, no qual os países centrais oferecem vacinas com redução ou isentas de Timerosal, enquanto os países periféricos fornecem VCT. Para os autores, a verdadeira injustiça reside na retirada do componente, que promoveria um colapso no abastecimento das vacinas, resultando no aumento das taxas de morbidade e mortalidade para as populações marginalizadas (144). Argumentos dessa ordem têm sido utilizados ao longo da história para justificar questões como trabalho infantil, indústria com potencial poluente e redução dos direitos trabalhistas, nos países periféricos (7).

Entretanto, o argumento de King et al, de que a retirada do Timerosal seria uma injustiça pois causaria desabastecimento de vacinas e de que muitas crianças não teriam acesso às imunizações pode ser confrontado, uma vez que vacinas contra Hepatite B em seringas preenchidas, por exemplo, podem ser comercializadas ao Governo brasileiro por um valor inferior àquelas multidoses (95). Diante do exposto, e partindo da percepção da $\mathrm{BI}$, que possui uma percepção crítica em relação às variadas formas de injustiça, nas quais as relações assimétricas de poder são desveladas, sobretudo ao discutir os macroproblemas cotidianos dos países periféricos (62) é permitido constatar que diversas formas de imperialismos são impostos aos países periféricos no que concerne ao tema das VCT, administradas à população infantil.

Nesse contexto, entendemos a pertinência do dialogo entre a $\mathrm{BI}$ e o conceito de Colonialidade da Vida, proposto por Nascimento, através do enfrentamento do imperialismo moral, que visa naturalizar, justificar e estruturar as desigualdades entre países centrais e periféricos e suas respectivas populações. A colonialidade, de forma hierarquizada e vertical, cria relações de poder através da imposição de 
padrões e regras de ordem econômica, moral, epistemológica e política (145). Nascimento relacionou a $\mathrm{BI}$ ao conceito de Colonialidade da Vida da seguinte forma:

\begin{abstract}
Seria exatamente esse processo de criar uma ontologia da vida que autorize pensar que algumas vidas são mais importantes do que outras, desde o ponto de vista político, fundando assim uma hierarquia e uma justificativa para dominação, exploração, submissão sob o pretexto de ser este um caminho para o desenvolvimento da vida menos desenvolvida" $(145$, p. 6$)$.
\end{abstract}

Existiria, portanto, uma vida com maior valor, diante de outras inferiores?! Por que algumas vidas são poupadas de exposição potencialmente danosa, enquanto outras são expostas indiscriminadamente e intencionalmente, devido a fatores econômicos?! A Desta forma, concordamos com a declaração de Garrafa, ao propor a DUBDH como antídoto (25), capaz de combater não apenas o duplo padrão em pesquisas, mas também o duplo padrão de segurança em vacinas, ao considerarmos que todos os seres humanos devem receber igualmente o melhor padrão de benefícios éticos na aplicação da medicina e nas pesquisas.

Assim, o duplo padrão de segurança em vacinas pediátricas fica evidenciado de duas formas: a primeira, e mais óbvia, diz respeito à utilização do mercúrio como conservante; a segunda, e não menos grave, diz respeito à administração da vacina Hepatite B a prematuros nas primeiras doze horas de vida, independente do resultado do exame para detecção da doença, muitas vezes ignorado durante o prénatal.

\title{
7.4 MUDANÇA DE PARADIGMA: PARTO DOMICILIAR E POSTERGAÇÃO DA VACINA HEPATITE B
}

Estudo recente de Dórea (2017) reitera o fato de que as crianças com idade inferior a seis meses são o grupo mais vulnerável à exposição ao Timerosal em vacinas, e por conseguinte, ao etilmercúrio, nos países periféricos, situação que é 
agravada pela vacinação materna, durante a gestação. Como foi verificado nos resultados desta pesquisa, gestantes podem ser imunizadas com até três vacinas que contém o conservante: Hepatite B (1 a 3 doses), Dupla adulto (1 a 3 doses) e Influenza (1 dose), independente da idade gestacional. O autor adverte para o estado de incerteza, que aponta para a associação entre o etilmercúrio e o risco de desordens do neurodesenvolvimento, como tiques, por exemplo. As evidências reforçam a necessidade de que VCT sejam substituídas por opções isentas de Timerosal nos países periféricos, tais como o 2-fenoxietanol(146) ou que as vacinas sejam acondicionadas em frascos monodose.

As vacinas em seringas preenchidas, por exemplo, oferecem segurança, pois além de não conterem o conservante, já possuem uma seringa acoplada (48) e não necessitam de manipulação no frasco, com reinserção de várias seringas, o que aumenta o risco de contaminação. $\mathrm{Na}$ Indonésia, por exemplo, parteiras administraram vacinas contra Hepatite B utilizando seringas preenchidas para imunizar bebês nascidos em casa, fazendo uso de uma estratégia inovadora no programa de imunizações, que elimina o desperdício e permite que se aproveite a oportunidade de administração da vacina sem o risco de desperdiçar a vacina (147).

No Brasil, a prática de parto domiciliar tornou-se ao longo dos anos uma questão descartada, cedendo lugar aos partos hospitalares, elevando sobremaneira o índice de cesarianas, o que Ivan Illich (1975) descreveria como medicalização da saúde. Porém, existe um movimento atual e crescente em torno do resgate pelas práticas de partos domiciliares, que tem alterado timidamente o cenário da imunização precoce contra Hepatite $B$ em recém-nascidos. Considera-se que o parto domiciliar planejado em áreas urbanas no Brasil está relacionado ao nível de escolaridade elevado e acesso à informação (148).

Ademais, partos acidentais em áreas urbanas, ou em regiões isoladas das regiões norte e nordeste do Brasil (148) permitem uma margem para postergação das primeiras vacinas, sobretudo a Hepatite B, contendo Timerosal. A plataforma do Datasus informa que entre 2009 a 2014, nasceram 150.994 crianças em parto domiciliar, sendo a região norte (80.685 nascimentos) seguida da região nordeste (43.411), sudeste (15.665), centro-oeste (6.892) e sul (4.341) (149).

A pesquisa de Marques et al (2016) revela que, na Amazônia ocidental, no 
estado de Rondônia, as populações cujo estilo de vida tradicional é preservado, mantêm o consumo elevado de peixe, bem como práticas de parto domiciliar e amamentação prolongada $(150,151)$. A pesquisa verificou que crianças nascidas no hospital receberam a primeira dose de VCT, Hepatite $B$, mais precocemente do que aquelas nascidas em domicílio (média de 1,5 versus 24,1 dias, respectivamente). Seguindo o mesmo padrão, a exposição ao etilmercúrio contido nas vacinas foi mais elevado em crianças nascidas no hospital, apresentando uma taxa de $75,8 \mathrm{~g}$ versus $49,3 \mathrm{~g}(152)$.

Reforçamos a premissa de que o processo de imunização é válido e eficaz, mas as práticas de utilização de vacinas contendo mercúrio, sobretudo a prematuros, devem ser reavaliadas e novo manejo deve ser programado. Para isto, ferramentas como os 4 "Pês" da Bioética de Intervenção, bem como os princípios da DUBDH e outros parâmetros éticos, como a redução de danos e o Princípio de Precaução devem ser observados pelos governos dos países periféricos, nas tomadas de decisões em saúde, com o objetivo de minimizar danos e fornecer proteção aos mais vulneráveis. 


\section{CONSIDERAÇÕES FINAIS}

O cotidiano da população infantil nos países periféricos é permeado por situações agravantes à vulnerabilidade inerente a esse grupo, através de exposições a substâncias potencialmente tóxicas, como o mercúrio utilizado como conservante de vacinas multidoses; agrotóxicos, situações como desnutrição, falta de saneamento básico e acesso à água potável. Ademais, a exposição ao mercúrio neurotóxico pode ocorrer concomitantemente a mais uma forma de apresentação do $\mathrm{Hg}$, especialmente o meHg, através da ingestão de peixes contaminados, ou nos estágios iniciais da vida: intraútero, com a exposição materna a vacinas contendo mercúrio, bebês prematuros, expostos precocemente a vacina Hepatite $B$ e ao longo dos seis primeiros meses de vida, para cumprir o calendário de vacinação obrigatório.

A Convenção de Minamata, ocorrida em 2013, que foi decisiva para a elaboração de um documento global e juridicamente vinculante sobre a eliminação do mercúrio em diversos setores, excluiu o mercúrio (Timerosal) da discussão sobre os produtos relacionados à saúde que receberam regulamentação. Sob o argumento de que o uso de vacinas multidoses é mais vantajoso economicamente para o uso em países periféricos, permanece a crença que as VCT são indispensáveis para o controle de doenças nos países pobres.

$\mathrm{Na}$ introdução desta dissertação foi afirmado que "a exposição intencional ao mercúrio em vacinas agrava desnecessariamente a exposição de fetos, recémnascidos e prematuros a neurotóxicos nos países periféricos". Assim, após o levantamento e análise dos resultados, mantemos a afirmação de que existem soluções viáveis, tais como outros conservantes ou vacinas monodose, de modo que a utilização do Timerosal como conservante de vacinas infantis deve ser banida. Ademais, percebeu-se que, no Brasil, o custo da vacina contra Hepatite $B$, em seringa preenchida, e por consequência, sem o conservante, é economicamente mais vantajosa. As vacinas multidoses possuem a desvantagem de promover um maior desperdício, maior chance de contaminação do produto pela reinserção de agulhas repetidas vezes no frasco, além da chance de diminuição da cobertura vacinal por 
recusa do profissional em não abrir o frasco multidose, caso não haja um número de pacientes relevante.

Considera-se a relevância dessa discussão sob a perspectiva da Bioética de Intervenção, desenvolvida na Cátedra Unesco de Bioética e, alinhada aos princípios da Declaração Universal sobre Bioética e Direitos Humanos, da Unesco. A análise do duplo padrão em vacinas pediátricas à luz da Bioética de Intervenção, crítica às formas de imperialismos morais e éticos foi extremamente pertinente, pois fundamentou-se numa análise a partir de uma visão local para uma questão persistente que faz parte do cotidiano brasileiro. Nesse sentido, a discussão a respeito dos quatro "Pês" da Bioética de Intervenção evidencia a necessidade de sua utilização como parâmetro ético na tomada de decisões em saúde e nas questões sanitárias dos países periféricos, a saber: prevenção de danos e iatrogenias; precaução frente ao desconhecido; prudência em relação aos avanços tecnológicos; e proteção das pessoas mais vulneráveis.

Consideramos essencial o aprofundamento das pesquisas sobre os níveis de desperdício de vacinas multidoses no Brasil, como uma alternativa que poderia viabilizar a utilização de vacinas monodose, sem o conservante Timerosal. Ademais, mudanças no manejo da vacinação infantil são necessárias e deveriam ser realizadas de forma urgente, especialmente no que concerne à população de recém-nascidos prematuros e de baixo peso, população que seria beneficiada caso os exames obrigatórios no pré-natal fossem, de fato, realizados. Consideramos que avaliações sobre uso de VCT em crianças que apresentam agravos neurológicos se fazem necessárias, a exemplo dos bebês nascidos com microcefalia, provavelmente por infecção pelo Zika vírus, sobretudo no Nordeste, região mais pobre e afetada pela epidemia crescente no Brasil. 


\section{REFERÊNCIAS}

1. Ministério da Saúde. Secretaria de Vigilância em Saúde. Departamento de Vigilância das Doenças Transmissíveis. Manual de Normas e Procedimentos para Vacinação. Brasília, DF. 2014.

2. Institute of Medicine (US). Immunization Safety Review Committee. Immunization Safety Review: Vaccines and Autism. Washington (DC): National Academies Press (US). 2004.

3. Rocha JBT, Aschner M, Dórea JG, Ceccatelli S, Farina M, Silveira LCL. Mercury Toxicity. Journal of Biomedicine and Biotechnology. 2012; 2.

4. Dórea JG. The neurological effects of prenatal and postnatal exposure to mercury need to include ethylmercury. Chemosphere. 2015; 139: 667-8.

5. Dórea JG Comments on neonatal hair-Hg and birth weight in China: mercury in rice and fish.Environ Pollut. 2014; 184: 654.

6. United Nations Environment Programme. Mercury: Time to Act. United Nations Environment Programme, 2013.

7. Geier DA, King PG, Hooker BS, Dorea JG, Kern JK, Sykes LK, et al. Thimerosal: Clinical, epidemiologic and biochemical studies. Clinica Chimica Acta. 2015; 444: $212-$ 220.

8. Tan M, Parkin JE. Route of decomposition of thiomersal (thimerosal). Int J Pharm, 2000; 208(1-2): 23-34.

9. Sykes LK, Geier DA, King PG, Kern JK, Haley BE, Chaigneau CG, et al. Thimerosal as discrimination: vaccine disparity in the UN Minamata Convention on mercury. Indian J Med Ethics. 2014; 11(4): 206-18.

10. Dórea JG. Exposure to mercury during the first six months via breast milk and vaccines: modifying risk factors. Am J Perinatol. 2007; 24: 387-400.

11. Dórea JG. Maternal smoking and infant feeding: breastfeeding is better and safer. Matern. Child Health J. 2007; 11: 287-291.

12. Dórea JG. Making sense of epidemiological studies of young children exposed to 
thimerosal in vaccines. Clin Chim Acta. 2010; 411(21-22): 1580-6.

13. Dórea JG. Exposure to Mercury and Aluminum in Early Life: Developmental Vulnerability as a Modifying Factor in Neurologic and Immunologic Effects. Int J Environ Res Public health. 2015; 12(2): 1295-1313.

14. Food and Drug Administration. Thimerosal in Vaccines. Disponível em: http://www.fda.gov/BiologicsBloodVaccines/SafetyAvailability/VaccineSafety/ucm096 228.htm. Acesso em 29/09/16.

15. Academy of Pediatrics. Joint Statement of the American Academy of Pediatrics and the United States Public Health Services. Pediatrics. 1999; 104(3), 568-569. Disponível em: http://pediatrics.aappublications.org/content/pediatrics/104/3/568.full.pdf. Acesso em 19/09/16.

16. American Academy of Family Physicians, American Academy of Pediatrics, Advisory Comittee on Immunization Practices, United States Public Health Services. Joint Statement Concerning Removal of Thimerosal from Vaccines. 2000. Disponível em: $\quad$ http://www.fda.gov/ohrms/dockets/dockets/04p0349/04p-0349-ref0001-06-Tab03-Concerns-Thimerosal-02-vol6.pdf. Acesso em 19/09/16.

17. World Health Organization. Global Advisory Committee on Vaccine Safety. Wkly Epidemiol Rec. 2012; 87(30): 281-28.

18. Beauchamp TL, Childress JF. Principles of Biomedical Ethics. $7^{\text {a }}$ ed. Nova York: Oxford University Press, 2013.

19. Garrafa V, Porto D. Intervention bioethics: a proposal for peripheral countries in a context of power and injustice. Bioethics. 2003; 17(5-6): 399-416.

20. Lessa SC, Schramm FR. Individual versus collective protection: bioethical analysis of the national program of mass child vaccination. Ciência \& Saúde Coletiva. 2015; 20(1): 115-124.

21. Garrafa V, Porto D. Verbetes: Bioética de intervención. In Tealdi, JC (org). Diccionário Latino-Americano de Bioética. Bogotá: Unibiblos/UNESCO. 2008.

22. Nascimento WF, Garrafa V. Por uma vida não colonizada: diálogo entre bioética de intervenção e colonialidade. Saúde Soc. 2011; 20(2): 287-99.

23. Garrafa V. Prefacio. In Giovanni Berlinguer. Bioética Cotidiana. Brasília: Editora UnB, 2004.

24. Organização das Nações Unidas para a Educação, a Ciência e a Cultura. 
Declaração universal sobre bioética e direitos humanos. Paris: Unesco; 2005. Disponível em: http://www.sbbioetica.org.br/wpcontent/uploads/2011/11/TEXTODADUBDH.pdf. Acesso em 06 set. 2015.

25. Garrafa V. Inclusão social no contexto politico da bioética. Rev Brasileira Bioética. 2005; 1(2): 122-32.

26. Harada M. Minamata disease: methylmercury poisoning in Japan caused by environmental pollution. Critical reviews in toxicology. 1995; 25(1): 1-24.

27. Bakir F, Damluji SF, Amin-Zaki L, Murtadha M, Khalidi A, al-Rawi NY, et al. Methylmercury poisoning in Iraq. Science. 1973;181(4096): 230-41.

28. United Nations Environment Programme. Minamata Convention on Mercury: Convention. Disponível em: http://www.mercuryconvention.org/Convention/tabid/3426/Default.aspx. Acesso em 07/07/16.

29. United Nations Environment Programme. Minamata Convention on Mercury: Text and Annexes. 2013. Disponível em: http://www.mercuryconvention.org/Portals/11/documents/Booklets/Minamata \%20Convention\%20on\%20Mercury_booklet_English.pdf. Acesso em 23/07/16.

30. United Nations Environment Programme. Global Mercury Assessment: Sources, Emissions, Releases and Environmental Transport. 2013. Disponível em: http://mww.unep.org/PDF/PressReleases/GlobalMercuryAssessment2013.pdf. Acesso em 05/07/16.

31. World Health Organization. Trace elements and human nutrition and health. Geneva.1996; 195-203.

32. World Health Organization. Infancy and early childhood, principles for evaluating health risks from chemicals. 1986.

33. Mahaffey KR, Rice GE, Swartout J. An Assessment of Exposure to Mercury in the United States: Mercury Study Report to Congress. Washington, DC: U.S. Environmental Protections Agency; 1997. Disponível em https://www3.epa.gov/ttn/atw/112nmerc/volume4.pdf. Acesso em 07/07/16.

34. Federal Register, 1979; 44: 3990.

35. Agency for Toxic Substances and Disease Registry. Toxicological profile for 
mercury. Atlanta, $\quad 1999 . \quad$ DAsponível em: http://www.atsdr.cdc.gov/toxprofiles/tp46.pdf. Acesso em 07/07/16.

36. Pichichero ME, Cernichiari E, Lopreiato J, Treanor J. Mercury concentrations and metabolism in infants receiving vaccines containing thiomersal: a descriptive study. Lancet. 2002; 360(9347): 1737-41.

37. Carneiro MFH. Avaliação da distribuição, metabolismo e nefrotoxicidade do Timerosal - um conservante a base de mercúrio usado em vacinas - utilizando modelos in vivo e in vitro [tese]. Ribeirão Preto: Faculdade de Ciências Farmacêuticas de Ribeirão Preto; 2014.

38. Rooney JP. The retention time of inorganic mercury in the brain-A systematic review of the evidence. Toxicol. Appl. Pharmacol. 2014; 274: 425-435.

39. Carneiro, MFH, Oliveira Souza JM, Grotto D, Batista BL, de Oliveira Souza, VC, Barbosa F Jr. A systematic study of the disposition and metabolism of mercury species in mice after exposure to low levels of thimerosal (ethylmercury). Environ. Res. 2014; 134: 218-227.

40. Dórea JG. Chemical mixtures, maternal exposure and infant neurodevelopment: Did we miss positive (breastfeeding) and negative (mercury) confounders? Neurotoxicology and teratology. 2014; 45: 93.

41. Ball LK, Ball R, Pratt RD. An assessment of thimerosal use in childhood vaccines. Peditrics. 2001; 107(5): 1147-54.

42. Dórea JG. Integrating experimental (in vitro and in vivo) neurotoxicity studies of low-dose thimerosal relevant to vaccines. Neurochem. Res. 2011; 36: 927-938.

43. Dórea JG. Low-dose mercury exposure in early life: Relevance of thimerosal to fetuses, newborns and infants. Curr. Med. Chem. 2013; 20: 4060-4069.

44. Clements CJ. The evidence for the safety of thiomersal in newborn and infant vaccines. Vaccine. 2004; 22: 1854-1861.

45. Thyssen JP, Linneberg A, Menne T, Johansen JD. The epidemiology of contact allergy in the general population - prevalence and main findings. Contact Dermat. 2007; 57: 287-99.

46. Dórea JG. Concern regarding early exposure to thiomersal and mercury poisoning: Comment on the article by Bensefa-Colas et al. Rev. Med. Interne. 2012; 
33: $115-116$.

47. Chhawchharia R, Puliyel JM. Controversies surrounding mercury in vaccines: autism denial as impediment to universal immunisation. Indian Journal of Medical Ethics. 2014; 11(4): 218-22.

48. Drain PK, Nelson CM, Lloyd JS. Single-dose versus multi-dose vaccine vials for immunization programmes in developing countries. Bulletin of the World Health Organization. 2003;81(10):726-31.

49. Lee BY, Norman BA, Assi TM, Chen S, Bailey RR, Rajgopal J, et al. Single versus Multi-Dose Vaccine Vials: An Economic Computational Model. Vaccine. 2010;19; 28(32): 5292-5300.

50. Homma et al. Vaccines, immunization and technological innovation: an update Ciência \& Saúde Coletiva. 2011; 16(2):445-458.

51. Potter VR. Bioethics: bridge to the future. Prentice-Hall. 1971.

52. Neves MDCP. A fundamentação antropológica da bioética. Bioética. 1996;4(1):716.

53. Pessini L. As origens da bioética: do credo bioético de Potter ao imperativo bioético de Fritz Jahr. Revista Brasileira de Bioética. 2013;21 (1):9-19.

54. Beecher HK. Ethics and clinical research. New England Journal of Medicine.1966; 274(24):1354-1360.

55. Pessini L. Introdução à edição brasileira. Prefácio. In: Beauchamp T L, Childress J F. Princípios de Ética Biomédica. São Paulo: Loyola. 2002.

56. National Commission for the Protection of Human Subjects of Biomedical and Behavioral Research. The Belmont Report. 1979. Disponível em: http://www.hhs.gov/ohrp/humansubjects/guidance/belmont.html. Acesso em 22/06/15.

57. Azambuja LEO de. A Teoria da Moralidade Comum e o princípio da Justiça na obra de Beauchamp e Childress. Tese. (Doutorado em Bioética) - Faculdade de Ciências da Saúde, Universidade de Brasília, Brasília, 2014.

58. Beauchamp TL, Childress JF. Princípios de ética biomédica. São Paulo: Edições Loyola; 2002.

59. Garrafa V. Ampliação e politização do conceito internacional de bioética. Revista 
Bioética. 2012; 20(1): 9-20.

60. Garrafa V, Pessini L (orgs). Bioética: Poder e Injustiça. São Paulo: Loyola, 2003.

61. Barbosa SN. A participação brasileira na construção da Declaração Universal sobre Bioética e Direitos Humanos da Unesco. Revista Brasileira de Bioética. 2006; 2(4): 423-42.

62. Garrafa V, Martorell LB. Bioética de Intervenção - uma breve síntese de seus fundamentos e aplicações em tempos de globalização e desigualdades sociais. In: Siqueira JE , Zoboli E, Sanches M, Pessini L. (orgs). Bioética clínica: memórias do XI Congresso Brasileiro de Bioética, do III Congresso Brasileiro de Bioética Clínica e da III Conferência Internacional sobre o Ensino da Ética - Brasília: CFM/SBB; 2016; 7392.

63. Porto D, Garrafa V. Bioética de intervenção: considerações sobre a economia de mercado. 2005; 13(1):111-123.

64. Garrafa V. Verbetes: Bioética de Intervención; imperialismo moral; Bioética y política. In: Tealdi, JC (org.) Diccionario Latino-Americano de Bioética. Buenos Aires, 2006.

65. Garrava V. Da bioética de princípios a uma bioética interventiva. Revista Bioética. 2009;13(1): 125-134.

66. United Nations Educational, Scientific and Cultural Organization. The precautionary principle on the Ethics of Scientific Knowledge and Technology. Unesco. Paris: 2005.

67. United Nations. Report of the United Nations Conference on Environment and Development, Annex I: Rio Declaration on Environment and Development; 1992.

68. Fischer AJ, Ghelardi G. The Precautionary Principle, Evidence-Based Medicine, and Decision Theory in Public Health Evaluation. Front Public Health. 2016;4:107.

69. Tagliabue G. The Precautionary principle: its misunderstandings and misuses in relation to "GMOs". N Biotechnol. 2016; 33(4): 437-9.

70. European Commission. Communication from the Commission on the precautionary principle, Brussels. 2000.

71. Raffensperger C, Schettler T, Myers N. Precaution: belief, regulatory system, and overarching principle.Int J Occup Environ Health. 2000; 6(4): 266-9. 
72. Raffensperger C, Tickner J (eds). Protecting Public Health and the Environment: Implementing the Precautionary Principle. Washington, DC: Island Press, 1999: 3534.

73. Dallari SG, Ventura D de FL. O princípio da precaução: dever do Estado ou protecionismo disfarçado? S. Paulo Perspect. 2002; 16(2): 53-63.

74. Ross WD. Lo correcto y lo bueno. Ediciones Sígueme. 1994.

75. Frankena W. Ethics, 2 ed. Englewood Cliffs, NJ: Prentice-Hall. 1973.

76. Bobbio N, Matteucci N, Pasquino G. Dicionário de Política, Brasília. Editora UnB. 2004;11: 611-621.

77. Garrafa V. Imperialismo ético (verbete). In: Tealdi JC, editor. Diccionário latinoamericano de bioética. Bogotá: Unibiblos/Organización de las Naciones Unidas para la Educación, la Ciencia y la Cultura; in press. 2008.

78. Garrafa V, do Prado MM. Changes in the Declaration of Helsinki: economic fundamentalism, ethical imperialism and social control. Cad. Saúde Pública. 2001; 17(6):1489-1496.

79. Garrafa V, Lorenzo C. Helsinque 2008: redução de proteção e maximização de interesses privados. Rev Assoc Med Bras 2009; 55(5): 497-520.

80. World Medical Association (WMA). Declaration of Helsinki. Amended by the 64th WMA General Assembly, Fortaleza, Brazil. 2013.

81. Hellmann F, Verdi M, Schlemper BR Jr, Caponi S. 50th anniversary of the Declaration of Helsinki: the double standard was introduced. Arch Med Res. 2014;45(7):600-1.

82. Nascimento, WFD, Martorell LB. A bioética de intervenção em contextos descoloniais. Rev. bioét. (Impr.) 2013; 21 (3): 423-31.

83. Ministério da Saúde. Calendário de vacinação atualizado já está em vigor. 2016.

Disponível em: http://www.brasil.gov.br/saude/2016/01/calendario-de-vacinacaoatualizado-ja-esta-em-vigor?

utm_source=feedburner\&utm medium=feed\&utm_campaign=Feed $\% 3 A+R s s-S a d e+$ (RSS+-+Sa\%C3\%Bade). Acesso em: 07/07/16.

84. Mathew JL. Vaccine science and commerce: never the twain shall meet? BMJ 2008; 336(7651): 974. 
85. Global Alliance (GAVI). Disponível em: http://www.gavi.orgl. Acesso em 19/09/16. 86. Martin JF, Marshall J. New tendencies and strategies in international immunization: GAVI and the Vaccine Fund. Vaccine. 2003; 21: 587-92.

87. Gavi's partnership model. Disponível em: http://www.gavi.org/about/gavispartnership-model/. Acesso em 19/09/16.

88. Puliyel JM, Shrivastava A. Global access to vaccines: Poor nations are being lured into a debt trap. BJM. 2008;336(7651):974-5.

89. Dhanasiri SK, Puliyel JM. Regulating vaccines: can health-economics tools be used profitably? Indian Pediatr. 2007; 44(1):11-4.

90. Arora R, Puliyel JM. Economic evaluation tailored to promote vaccine uptake: how third world consumers can respond. Expert Rev Pharmacoecon Outcomes Res. $2005 ;(5):$ 515-6.

91. Puliyel JM. Vaccine Policy and Advance Market Commitments. Economic \& Political Weekly. 2011; 46 (44-45): 18-19.

92. Barocchi MA, Rappuoli R. Delivering vaccines to the people who need them most. Philos Trans R Soc Lond B Biol Sci. 2015;370(1671).

93. Milstien JB, Kaddar $M$. The role of emerging manufacturersin access to innovative vaccines of public health importance. Vaccine 2010; 28:2115-2121.

94. Secretaria de Estado da Saúde. Instituto Butantan. Profissional de Saúde. Bula: Vacina adsorvida hepatite b recombinante. 2014. Disponível em: https://remediobarato.com/vacina-recombinante-contra-hepatite-b-bula-completainstituto-butantan--para-o-profissional.html. Acesso em 19/09/16.

95. Agência Nacional de Vigilância Sanitária. Preços máximos de medicamentos por princípio ativo para compras públicas preço fábrica e preço máximo de venda ao Governo. $2016 . \quad$ Disponível em: http://portal.anvisa.gov.br/documents/374947/2829072/LISTA_CONFORMIDADE_G OV_2016-10-20.pdf/20b61fe1-f8a9-41ae-a55d-cb8613953dd8. Acesso em 22/09/16.

96. Glaxo Smith kline. Bula Vacina hepatite b recombinante. Disponível em: http://www.xock.org/b/bulas/medicamentos/vacinas-em-geral/antigenos-virais-antihepatite-b/vacina-hepatite-b-recombinantel. Acesso em 22/09/16.

97. Gibbs G. Análise de dados qualitativos. Porto Alegre: Ed. Artmed, 2009. 
98. Ministério da Saúde. Programa Nacional de Imunizações. Calendário Nacional de Imunizações. Disponível em: http://portalarquivos.saude.gov.br/campanhas/pni/. Acesso em: 18/07/16.

99. Ministério da Saúde. Campanha nacional de vacinação contra a influenza. Informe técnico. 2015.2 Disponível em: (http://portalsaude.saude.gov.br/images/pdf/2015/abril/09/Informe-Cp-Influenza---2503-2015-FINAL..pdf) Acesso em 18/07/16.

100. Sociedade Brasileira de Imunizações. Calendário de vacinação do prematuro. Disponível em: http://sbim.org.br/calendarios-de-vacinacao. Acesso em: 19/07/16.

101. Ministério da Saúde. Fundação Nacional de Saúde. Manual dos centros de referência de imunobiológicos especiais. 2001. Disponível em: http://www.infectologia.org.br/admin/zcloud/137/2016/07/manual_cries.pdf. Acesso em 19/07/16.

102. Ministério da Saúde. Manual dos Centros de Referência para Imunobiológicos Especiais. $4^{\circ}$ edição: 2014. Disponível em: http://www.saude.pr.gov.br/arquivos/File/01VACINA/manual_crie_.pdf. Acesso em 20/07/16.

103. Ministério da Saúde. Portaria $n^{\circ}$ 828, de 5 de Julho de 2016. Disponível em: http://www.brasilsus.com.br/index.php/legislacoes/sas/8357-portaria-n-828-de-5-dejulho-de-2016. Acesso em 20/07/16.

104. Ministério da Saúde. Manual Técnico: Pré-natal e puerpério atenção qualificada e humanizada. 2006.

105. Ministério da Saúde. Caderneta da Gestante. 3ed. 2016.

106. Ministério da Saúde. Secretaria de Atenção à Saúde. Tabela de Procedimentos do SUS. Tabela de Procedimentos, Medicamentos, Órteses, Próteses e Materiais Especiais do SUS. 2012.2 Disponível em: http://www.lagoasanta.mg.gov.br/attachments/article/1827/TABELA\%20SIA.SUS.pdf. Acesso em 22/09/16.

107. Sociedade Brasileira de Pediatria. Calendário de Vacinação. Recomendação da Sociedade Brasileira de Pediatria. 2016. Disponível em: http://www.sbp.com.br/src/uploads/2012/12/Calendrio-de-Vacinao-da-SBP-2016.pdf. Acesso em 06/09/16. 
108. Feitosa SF, Nascimento WFD. A bioética de intervenção no contexto do pensamento latino-americano contemporâneo. Rev. bioét.(Impr.). 20015: 23(2), 27784.

109. Garrafa V. Contra o monopólio da saúde. Rio de Janeiro: Achiamé; 1981.

110. Garrafa V, Porto D. Bioética, poder e injustiça: por uma ética de intervenção. Mundo Saúde. 2002;26(1):6-15.

111. Martorell LB. Análise Crítica da Bioética de Intervenção: um Exercício de Fundamentação Epistemológica. Tese (Doutorado em Bioética) - Faculdade de Ciências da Saúde, Universidade de Brasília, Brasília, 2015.

112. Garrafa V. Ética de la investigación biomédica. In: Manual de Bioética para Periodistas. Unesco, 2015.

113. Garrafa V, Solbakk JH, Vidal S, Lorenzo C. Between the needy and the greedy: the quest for a just and fair ethics of clinical research. J Med Ethics 2010;36:500-504.

114. Celso H. de Oliveira; Murilo Rebechi; Paula C Quagliara. Sensibilidade ao Timerosal e seu uso em colírios no Brasil. Rev. bras. alerg. Imunopatol. 2006; 9(1) 2627.

115. Agência Nacional de Vigilância Sanitária. Resolução RE n528, de 17 de abril de 2001. Disponível em: http://www.cvs.saude.sp.gov.br/zip/U_RDC-ANVISA528_170401.pdf. Acesso em 08/09/15.

116. Brasil. Lei $n^{\circ}$. 8080, de 19 de setembro de 1990. Dispõe sobre as condições para a promoção, proteção e recuperação da saúde, a organização e o funcionamento dos serviços correspondentes. Diário Oficial União, Brasília (DF) 1990.

117. Brasil. Lei $n^{\circ}$. 9782, de 26 de janeiro de 1999. Define o Sistema Nacional de Vigilância Sanitária, cria a Agência Nacional de Vigilância Sanitária, e dá outras providências. Diário Oficial União, Brasília (DF) 1999.

118. Leite DF, Barbosa PFT, Garrafa V. Auto-Hemoterapia, Intervenção do Estado e Bioética. Rev Assoc Med Bras. 2008; 54(2): 183-8.

119. Cruz MR, Trindade EDS. Bioética de intervenção: uma proposta epistemológica e uma necessidade para sociedades com grupos sociais vulneráveis. Revista Brasileira de Bioética. 2006: 2(4), 483-99.

120. Illich I. Nemesis Médica: la expropiacion de la salud. Barral Editores, 1975. 
121. Berlinguer G. Bioética da prevenção. Revista Bioética. 2009: 2(2).

122. Kottow M. A bioethical jaccuse: analysis of the discussion around thiomersal in Chile. Medwave. 2014;26:14(2):e5923.

123. Alma MM, Katia AV, Jorge J de la J, Vivian LF, Miguel OG, Erna RM, et al. Seguridad de las vacunas que contienen timerosal: Declaración del Comité Consultivo de Inmunizaciones (CCI) de la Sociedad Chilena de Infectología. Rev Chil Infect 2007; 24 (5): 372-376.

124. Rada G. Thimerosal in vaccines - white, black, or quite the opposite? Medwave 2014;14(2):5929.

125. Lessa SDC. Vacinação Infantil e os eventos adversos pós-vacinação: contribuição da Bioética para implantação de políticas compensatórias no Brasil. Tese (Doutorado em Bioética) - Faculdade de Ciências da Saúde, Universidade de Brasília, Brasília, 2013.

126. Ten Have, H., \& Jean, M. (Eds.). The UNESCO universal declaration on bioethics and human rights: Background, principles and application. UNESCO. 2009.

127. D’Empaire G. Article 10: Equality, Justice and Equity. In: Ten Have, H., \& Jean, M. (Eds.). The UNESCO universal declaration on bioethics and human rights: Background, principles and application. UNESCO, 2009.

128. Pellegrino ED. (2009) Article 4: Benefit and harm. In Ten Have, H., \& Jean, M. (Eds.). The UNESCO universal declaration on bioethics and human rights: Background, principles and application. UNESCO, 2009.

129. Neves MP. Article 8: Respect for Human Vulnerability and Personal Integrity. In: Ten Have HAMJ, Jean MS. The UNESCO Universal Declaration on Bioeth ics and Human Rights: Background, principles and application. Unesco, 2009.

130. Neves MP. Sentidos da vulnerabilidade: característica, condição, princípio. Revista Brasileira de Bioética. 2006; 2(2):57-72.

131. Paranhos FRL., Garrafa V, Melo RLD. Estudo crítico do princípio de benefício e dano. Rev. bioét. (Impr.). 2015; 23 (1): 12-9.

132. Neves MP. article 8: Respect de la vulnerabilité humaine et de l'integrité personnelle. In UNESCO: La Déclaration Universelle sur la Bioéthique et les Droits de I'homme: histoire, principes et application. Paris: UNESCO; 2009. p. 167-77.) 
133. Convenção Americana sobre Direitos Humanos (Pacto de San José da Costa Rica). Planalto. [Online].1969. Disponível em: http://aidpbrasil.org.br/arquivos/anexos/conv_idh.pdf. Acesso em 19/09/16.

134. Isasi RM, Annas GJ. Arbitrage, bioethics, and cloning: the ABCs of gestating a United Nations cloning convention. Case W. Res. J. Int'I L. 2003; 35: 397-414.

135. Código de Nuremberg. Tribunal Internacional de Nuremberg, 1947. Disponível em: http://www.ufrgs.br/bioetica/nuremcod.htm. Acesso em 16 set. 2016.

136. Oliveira AASD. Interface entre bioética e direitos humanos: o conceito ontológico de dignidade humana e seus desdobramentos. Revista Bioética. 2009; 15(2):170-85.

137. Tickner JA, Hoppin P. Children's environmental health: a case study in implementing the precautionary principle. Int J Occup Environ Health. 2000;6(4):281-8.

138. Quijano RF. Risk assessment in a third-world reality: an endosulfan case history. Int J. Occup Environ Health. 2000;6(4):312-7.

139. Corgozinho MM, Oliveira AASA. Equidade em saúde como marco ético da bioética. Saúde Soc. São Paulo. 2016; 25(2): 431-441.

140. Barros FPC, Sousa MF. Equidade: seus conceitos, significações e implicações para o SUS. Saúde Soc. São Paulo. 2016; 25(1): 9-18.

141. Fortes PAC, Zoboli ELCP. Bioética e Saúde Pública. Cadernos. Centro Universitário São Camilo, São Paulo. 2006; 12 (2): 41-50.

142. Fortes PAC. A equidade no sistema de saúde na visão de bioeticistas brasileiros. Rev Assoc Med Bras. 2010; 56(1): 47-50.

143. Kalckmann S, Santos CG, Luis EB, Cruz VM. Racismo Institucional: um desafio para a eqüidade no SUS? Saúde Soc. São Paulo. 2007; 16(2): 146-155.

144. King K, Paterson M, Green, SK. Global justice and the proposed ban on thimerosal-containing vaccines. Pediatrics, 2013:131(1);154-156.

145. Nascimento WFD. A modernidade vista desde o Sul: perspectivas a partir das investigações acerca da colonialidade. Padê: Estudos em filosofia, raça, gênero e direitos humanos (encerrada). 2010:2(1).

146. Dórea JG. Low-dose Thimerosal in pediatric vaccines: Adverse effects in perspective. Environ Res. 2017; 152:280-293. 
147. Sutanto A; Suarnawa IM; Nelson CM, Stewart T, Soewarso TI.Home delivery of heat-stable vaccines in Indonesia: outreach immunization with a prefilled, single-use injection device. Bull World Health Organ. 1999; 77(2):119-26.

148. Colacioppo PM, Koiffman MD, Riesco MLG, Schneck CA. \& Osava RH. Parto domiciliar planejado: resultados maternos e neonatais. Revista de Enfermagem Referência, 2010;(2):81-90.

149. Ministério da Saúde. Nascidos vivos no Brasil entre 2009 a 2014. Disponível em: http://tabnet.datasus.gov.br/cgi/tabcgi.exe?sinasc/cnv/nvuf.def. Acesso em 24/10/16.

150. Marques RC, Abreu L, Bernardi JVE, Dórea JG. Neurodevelopment of Amazonian children exposed to ethylmercury (from thimerosal in vaccines)and methylmercury (from fish). Environ. Res. 2016;149:259-65 .

151. Vieira SM, Almeida R, Holanda IBB, Mussy MH, Galvão RCF, Crispim PTB, Dórea JG, Bastos WR. Total and methyl-mercury in hair andmilk of mothers living in the city of Porto Velho and in villages along the RiMadeira Amazon, Brazil. Int. J. Hyg. Environ. Health. 2013; 216 :682-689.

152. Marques RC, Dórea JG, Manzatto AG, Bastos WR, Bernardi JVE, Malm O. Time of perinatal immunization, thimerosal exposure andneurodevelopment at 6 months in breastfed infants. Acta Paediatr. 2007;96(6):864-8. 


\section{ANEXOS}

\section{ANEXO A - VACINAS, LABORATÓRIOS, NÚMERO DE DOSES E VALIDADE DE VACINAS ADMINISTRADAS NO DF.}

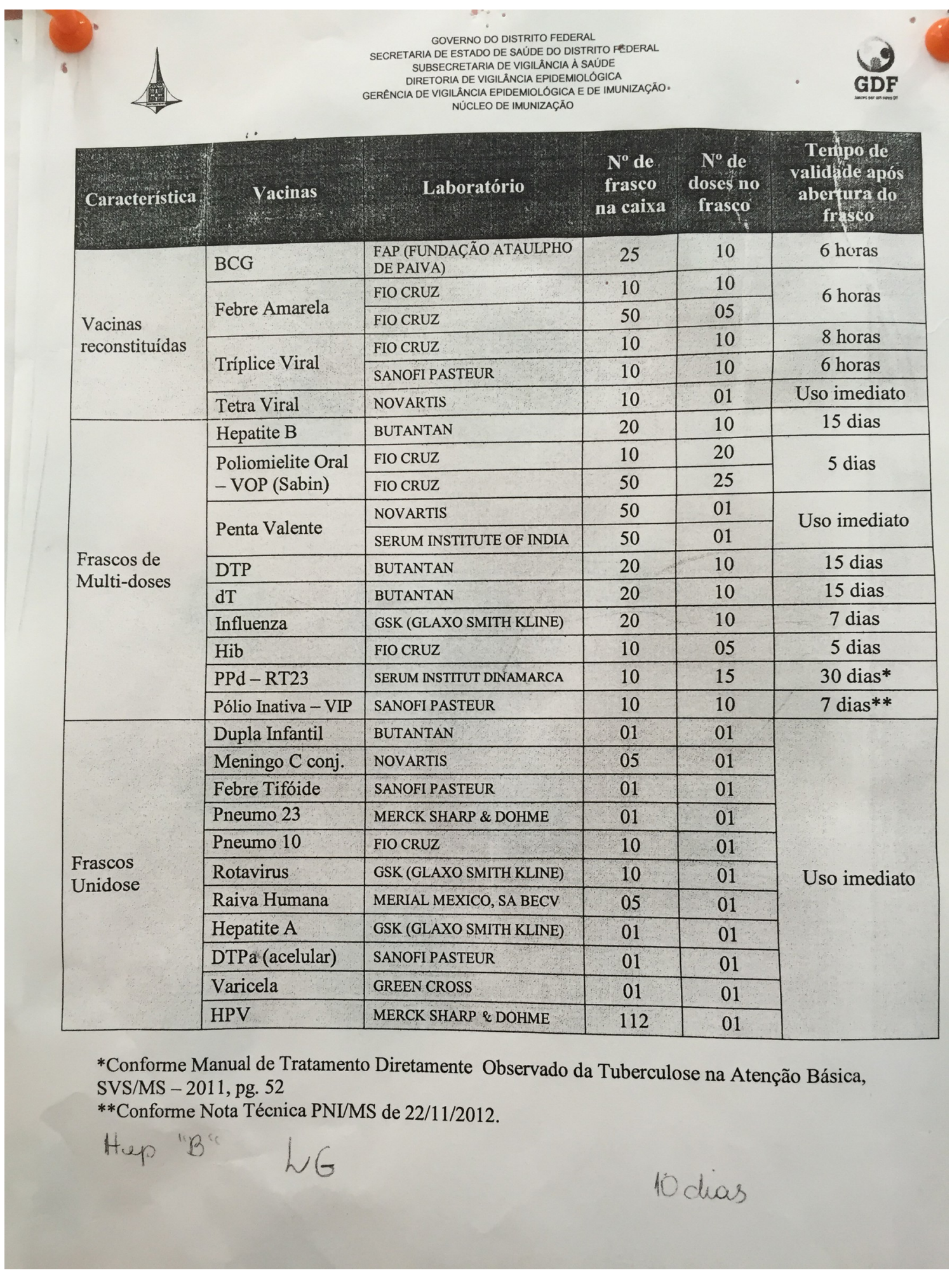




\section{ANEXO B - DIAS E LOCAIS DE APLICAÇÃO DAS VACINAS BCG E FEBRE} AMARELA NA REGIÃO CENTRO-NORTE DO DF.

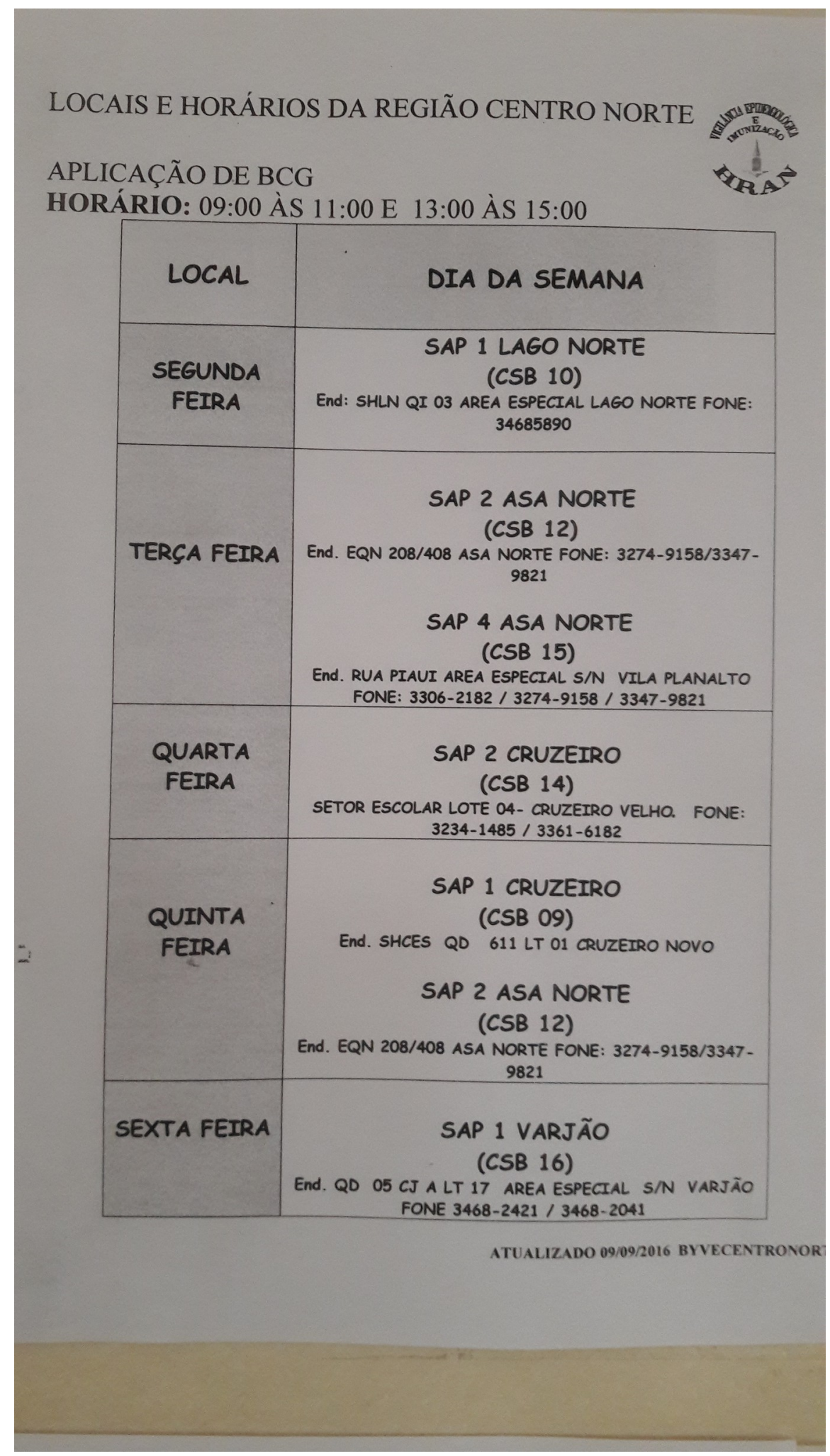




\section{ANEXO C - FALTA DE VACINA NO MERCADO E ALTO CUSTO}

\section{Fwd: Chegada pequeno lote vacina Hexa}

1 mensagem

Caetano <caetanof12@gmail.com>

9 de outubro de 2016 16:10

Para: Tati Tim <tatiteixeira.vaz@gmail.com>

Mensagem encaminhada -

De: Imunocentro - Clinica de vacinas <lembrete.vacina@imunocentro.com.br>

Data: 5 de outubro de 2016 19:35

Assunto: Chegada pequeno lote vacina Hexa

Para: caetanof12@gmail.com

ATENÇÃO: Esta mensagem foi gerada automaticamente pelo sistema. Favor não responder a este e-mail, pois as mensagens endereçadas a este endereço eletrônico não serão lidas ou respondidas, sendo apagadas periodicamente de forma automática.

Prezado(a) Senhor(a),

A clínica de vacinas IMUNOCENTRO informa que recebeu pequena quantidade da vacina Hexa acelular que estava em falta no mercado. Infelizmente isto não significa a regularização do fornecimento. Segundo o laboratório produtor, a normalização só ocorrerá a partir de 2017. A venda será a partir de amanhã, 06/10/2016, às $8 \mathrm{~h}$, por $\mathrm{R} \$ 690,00$ (cartão débito/crédito ou parcelado $10 \mathrm{X}$ sem juros) ou com $5 \%$ de desconto para pagamentos em dinheiro ou cheque à vista.

Como Lucas Caetano Paz De Oliveira tinha retorno dessa vacina cuja aplicação estava prevista para o dia 06/08/2016, e para que não haja comprometimento do nível de proteção do(a) paciente, recomendamos que a imunização seja realizada o mais breve possível.

Ressaltamos que este aviso não garante a reserva da vacina. $O$ atendimento será realizado por ordem de chegada.

Colocamo-nos à disposição para quaisquer informações adicionais, lembrando que é sempre recomendável buscar orientação com o médico do paciente.

Atenciosamente,

Clínica Imunocentro

Brasília/DF

Unidade Asa Sul: (61) 3346-0101 atendimento.asasul@imunocentro.com.br

Unidade Asa Norte: (61) 3272-0101 atendimento.asanorte@imunocentro.com.br

www.imunocentro.com. br

Clínica Imunocentro - A primeira clínica de vacinação do DF a obter o selo de qualidade da SBIm - Sociedade Brasileira de Imunizações e também a primeira clínica da Região Centro-Oeste Autorizada pela ANVISA a emitir o CIVP - Certificado Internacional de Vacinação ou Profilaxia. Quando se prima pela qualidade, o reconhecimento ocorre naturalmente. 


\title{
ANEXO D - JOINT STATEMENT OF THE AMERICAN ACADEMY OF PEDIATRICS AND THE UNITED STATES PUBLIC HEALTH SERVICE
}

\author{
JOINT STATEMENT OF THE AMERICAN ACADEMY OF \\ PEDIATRICS (AAP) AND THE UNITED STATES PUBLIC \\ HEALTH SERVICE (USPHS)
} \begin{tabular}{l}
\hline ABBREVIATIONS. FDA, Food and Drug Administration; USPHS, \\
US Public Health Service; AAP, American Academy of Pediatrics; \\
HBsAg, hepatitis B surface antigen; ACIP, Advisory Committee \\
on Immunization Practices; COID, AAP Committee on Infectious
\end{tabular} Diseases.

$\mathrm{T}$

he Food and Drug Administration (FDA) Modernization Act of 1997 called for the FDA to review and assess the risk of all mercury containing food and drugs. In line with this review, US vaccine manufacturers responded to a December 1998 and April 1999 FDA request to provide more detailed information about the thimerosal content of their preparations that include this compound as a preservative. Thimerosal has been used as an additive to biologics and vaccines since the 1930s because it is very effective in killing bacteria used in several vaccines and in preventing bacterial contamination, particularly in opened multidose containers. Some but not all of the vaccines recommended routinely for children in the United States contain thimerosal.

There is a significant safety margin incorporated into all the acceptable mercury exposure limits. Furthermore, there are no data or evidence of any harm caused by the level of exposure that some children may have encountered in following the existing im munization schedule. Infants and children who have received thimerosal-containing vaccines do not need to be tested for mercury exposure.

The recognition that some children could be exposed to a cumulative level of mercury over the first 6 months of life that exceeds one of the federal guidelines on methyl mercury now requires a weighing of two different types of risks when vaccinating infants. On the one hand, there is the known serious risk of diseases and deaths caused by failure to immunize our infants against vaccine-preventable infectious diseases; on the other, there is the unknown and probably much smaller risk, if any, of neurodevelopmental effects posed by exposure to thimerosal. The large risks of not vaccinating children far outweigh the unknown and probably much smaller risk, if any, of cumulative exposure to thimerosal-containing vaccines over the first 6 months of life.

Nevertheless, because any potential risk is of concern, the US Public Health Service (USPHS), the American Academy of Pediatrics (AAP), and vaccine

The recommendations in this statement do not indicate an exclusive course of treatment or serve as a standard of medical care. Variations, taking into account individual circumstances, may be appropriate.

PEDIATRICS (ISSN 0031 4005). Copyright $\odot 1999$ by the American Academy of Pediatrics. manufacturers agree that thimerosal-containing vaccines should be removed as soon as possible. Similar conclusions were reached this year in a meeting attended by European regulatory agencies, the European vaccine manufacturers, and the US FDA, which examined the use of thimerosal-containing vaccines produced or sold in European countries. The USPHS and the AAP are working collaboratively to ensure that the replacement of thimerosal-containing vaccines takes place as expeditiously as possible while at the same time ensuring that our high vaccination coverage levels and their associated low disease levels throughout our entire childhood population are maintained.

The key actions being taken are:

1. A formal request to manufacturers for a clear commitment and a plan to eliminate or reduce as expeditiously as possible the mercury content of their vaccines.

2. A review of pertinent data in a public workshop.

3. Expedited FDA review of manufacturers' supplements to their product license applications to eliminate or reduce the mercury content of a vaccine.

4. Provide information to clinicians and public health professionals to enable them to communicate effectively with parents and consumer groups.

5. Monitoring immunization practices, future immunization coverage, and vaccine-preventable disease levels.

6. Studies to better understand the risks and benefits of this safety assessment.

The USPHS and AAP continue to recommend that all children should be immunized against the diseases indicated in the 1999 Recommended Childhood Immunization Schedule of the American Academy of Pediatrics, the Advisory Committee on Immunization Practices (ACIP) of the Centers for Disease Control and Prevention (CDC), and the American Academy of Family Physicians (AAFP). Given that the risks of not vaccinating children far outweigh the unknown and much smaller risk, if any, of exposure to thimerosalcontaining vaccines over the first 6 months of life, clinicians and parents are encouraged to immunize all infants even if the choice of individual vaccine products is limited for any reason. Although there is a margin of safety with existing vaccines containing thimerosal, there are steps that can be taken to increase that margin even further. Clini- 
cians and parents can take advantage of the flexibility within the existing schedule for infants born to hepatitis B surface antigen (HBsAg)-negative women to postpone the first dose of hepatitis B vaccine from birth until 2 to 6 months of age when the infant is considerably larger. Preterm infants born to HBsAg-negative mothers should similarly receive hepatitis $B$ vaccine, but ideally not until they reach term gestational age and a weight of at least $2.5 \mathrm{~kg}$. Because of the substantial risk of disease, there is no change in the recommendations for infants of HBsAg-positive mothers or of mothers whose status is not known.

Also, in populations where HBsAg screening of pregnant women is not routinely performed, vaccination of all infants at birth should be maintained, as is currently recommended.

In addition to the key actions mentioned above, the USPHS Advisory Committee on Immunization Practices (ACIP) and the AAP Committee on Infectious Diseases (COID) will be reviewing these issues and may make additional statements. 
ANEXO E - THE SAFETY OF THIOMERSAL, OMS, 2012.

\section{Global Advisory Committee on Vaccine Safety, June 2012}

The Global Advisory Committee on Vaccine Safety (GACVS), an expert clinical and scientific advisory body, was established by WHO to provide independent, scientifically rigorous advice on vaccine safety issues of potential global importance. ${ }^{1}$ GACVS held its 26 th meeting in Geneva, Switzerland, on 6-7 June 2012. ${ }^{2}$ The committee reviewed the following specific topics:

- the safety of thiomersal;

- the safety of aluminium adjuvants;

- the safety profile of influenza vaccines during pregnancy.

It also reviewed 3 general issues for vaccine pharmacovigilance:

- safety of immunization during pregnancy and lactation;

- causality assessment for serious individual cases of adverse events following immunization (AEFI);

- core variables for AEFI monitoring.

\section{Thiomersal in vaccines}

In 1999, concerns were raised in the United States of America (USA) regarding exposure to mercury following immunization with thiomersal-containing vaccines. This was based on the calculation that the cumulative amount of mercury in primary infant immunization schedules in the USA potentially exceeded the recommended threshold set by its Environmental Protection Agency for methyl mercury. Hence, the policy decision in the USA to use only vaccines without thiomersal was based on a precautionary principle founded on the presumption of equal pharmacokinetics of ethyl mercury and methyl mercury, despite the fact that thiomersal contains only ethyl mercury.

Between 2002 and 2008, GAVCS reviewed several pharmacokinetic and epidemiological studies concerning thiomersal. Pharmacokinetic data in human infants, including premature and low birth-weight infants, established that the half-life of ethyl mercury is 3-7 days, and that ethyl mercury is efficiently excreted in the stools and does not accumulate over the long-term in blood, since levels returned to baseline within 30 days of vaccination.

\section{Comité consultatif mondial de la Sécurité vaccinale, juin 2012}

Le Comité consultatif mondial de la Sécurité vaccinale (GACVS), un organe consultatif, composé de spécialistes des questions scientifiques et cliniques, a été créé par l'OMS pour traiter en toute indépendance et avec la rigueur scientifique voulue des problèmes de sécurité vaccinale pouvant avoir une importance mondiale. ${ }^{1}$ Le GACVS a tenu sa $26^{\mathrm{e}}$ réunion à Genève (Suisse) les 6 et 7 juin 2012. ${ }^{2}$ Il s'est penché sur les questions spécifiques suivantes:

- l'innocuité du thiomersal;

- l'innocuité des adjuvants à base d'aluminium;

- le profil d'innocuité des vaccins antigrippaux pendant la grossesse.

Il a aussi étudié 3 autres questions, d'ordre général, relatives à la pharmacovigilance des vaccins:

- l'innocuité de la vaccination pendant la grossesse et l'allaitement;

- l'évaluation du lien de causalité dans les cas de manifestations postvaccinales indésirables (MAPI) graves;

- les variables fondamentales pour le suivi des MAPI.

Présence de thiomersal dans les vaccins

En 1999, on s'est inquiété, aux États-Unis, d'une exposition au mercure après l'administration de vaccins contenant du thiomersal, car on a calculé que la quantité cumulée de mercure que supposaient les calendriers de vaccination initiale des nourrissons pouvait dépasser le seuil recommandé, fixé par l'Agence de Protection de l'Environnement concernant le méthylmercure. Il a donc été décidé, par précaution, que les États-Unis n'utiliseraient que des vaccins ne contenant pas de thiomersal, en partant de l'hypothèse que la pharmacocinétique de l'éthylmercure et celle du méthylmercure étaient identiques, bien que le thiomersal ne soit composé que d'éthylmercure.

Entre 2002 et 2008, le GACVS a examiné plusieurs études pharmacocinétiques et épidémiologiques portant sur le thiomersal. Les données sur la pharmacocinétique chez le nourrisson, y compris prématuré et de petit poids à la naissance, montraient que la demi-vie de l'éthylmercure était de 3 à 7 jours, qu'il était efficacement excrété dans les selles et qu'il ne s'accumulait pas durablement dans le sang puisque les concentrations revenaient aux niveaux de référence moins de 30 jours après la vaccination. See No. 41, 1999, pp. 337-338.
GACVS invited additional experts to present and discuss evidence related to parti-
cular topics. These experts included persons affiliated with: Bambino Gesiù Hospital,
Rome, Italy; Center for Biologics Evaluation and Research (U.S. F.D.A), Rockville MD,
USA; John Hopkins Bloomberg School of Public Health, Baltimore MD, USA; Pro-
gram for Applied Technologies in Health, Seattle, USA; Rochester General Hospital
Research Institute, Rochester NY, USA; Shantha Biotechnics Limited, Hyderabad,
India; University of California, Los Angeles CA, USA; University of Washington,
Seattle WA, USA; Uppsala Monitoring Centre, Uppsala, Sweden.

RELEVE EPIDEMIOLOGIQUE HEBDOMADAIRE, № 30, 27 JUILLET 2012

\begin{abstract}
Voir № 41,1999 , pp. 337-338.
Le GACVS a invité d'autres experts à présenter et à analyser des données relatives à des sujets particuliers. Parmi eux figuraient des personnes affiliées à: I'Hôpital Bambino Gesù de Rome (Italie); le Center for Biologics Evaluation and Research (U.S. F.D.A), Rockville MD (États-Unis); la John Hopkins Bloomberg School of Public Health, Baltimore MD (Etats-Unis); le Program for Applied Technologies in Health, Seattle (Etats-Unis); le Rochester General Hospital Research sity of Californit Unis); I'Uppsala Monitoring Centre, Uppsala (Suède).
\end{abstract}


At the June 2012 meeting, GACVS reviewed the most recently available information concerning the safety of thiomersal since it last reviewed this topic in 2008. A comprehensive review identified 28 publications that addressed mercury blood levels in the short and long term following vaccine administration, and epidemiological studies that examined the relation between thiomersal receipt and several health outcomes. Three ecological studies suggesting an association between thiomersal and neurodevelopmental disorders were found to be fraught with methodological flaws. In addition, the continuous increase in the number of cases of autism diagnosed in the USA despite removal of thiomersal from most vaccines strongly argues against a causal association (fulfilling the exposure and removal criteria). All other studies reviewed, which were conducted with more robust epidemiological designs and in different countries, failed to identify any association with neurodevelopmental disorders.

Recently published studies confirm that in all populations studied, including pre-term and low birth-weight babies, the half-life of ethyl mercury in blood is between 3 and 7 days. A quantitative risk assessment model for cumulative toxicity of thiomersal in humans by US Federal Drug Administration (FDA) was also reviewed. This methodology is based on a pharmacokinetic model of ethyl mercury and provides a framework for interpreting studies in animals and humans that evaluate linkages among dose, blood and brain levels, and toxicity. Using this framework the GACVS concluded that animal or human toxicity studies suggest that the levels of ethyl mercury attained in the blood and brain from cumulative doses of vaccines do not reach toxic levels, making biologically implausible any relation between thiomersal in vaccines and neurological toxicity.

Based on the current evidence, GACVS considers that no additional studies of the safety of thiomersal in vaccines are warranted and that available evidence strongly supports the safety of the use of thiomersal as a preservative for inactivated vaccines. GACVS believes that consideration of additional evidence suggestive of the contrary should be based on studies using the same high standards of epidemiological and causal inference needed for scientific research. Thiomersal allows millions of people worldwide to have access to life-saving vaccines and to date, no other safer and equally efficacious alternative has been identified for many vaccines.

\section{Aluminium adjuvants}

The GACVS reviewed 2 published papers alleging that aluminium in vaccines is associated with autism spec-
Lors sa réunion de juin 2012, le GACVS a examiné les informations disponibles les plus récentes sur l'innocuité du thiomersal depuis qu'il avait étudié cette question pour la dernière fois, en 2008. Une revue de littérature complète a permis de recenser 28 publications sur les concentrations de mercure dans le sang à court terme et à long terme après l'administration d'un vaccin et des études épidémiologiques portant sur le lien entre l'exposition au thiomersal et plusieurs conséquences sur la santé Trois études écologiques qui semblaient indiquer l'existence d'un lien entre le thiomersal et des troubles du développement neurologique se sont avérées comporter des failles méthodologiques. En outre, l'augmentation constante du nombre des cas d'autisme diagnostiqués aux États-Unis malgré le retrait du thiomersal de la plupart des vaccins tend à démontrer de manière convaincante l'absence de lien de cause à effet (lorsque les critères d'exposition et de retrait sont remplis). Toutes les autres études examinées, qui ont été menées avec des structures épidémiologiques plus solides et dans différents pays, n'ont mis en évidence aucun lien avec des troubles du développement neurologique.

Des études publiées récemment confirment que, dans l'ensemble des populations étudiées, y compris les nourrissons prématurés et de petit poids à la naissance, la demi-vie de l'éthylmercure dans le sang est de 3 à 7 jours. Un modèle d'évaluation quantitative des risques concernant la toxicité cumulative du thiomersal chez l'homme, réalisée par la Federal Drug Administration (FDA) des États-Unis, a également été examiné. Cette méthodologie, basée sur un modèle pharmacocinétique de l'éthylmercure, fournit un cadre pour interpréter les études qui évaluent, chez l'animal et chez l'homme, les liens entre la dose, les concentrations dans le sang et dans le cerveau, et la toxicité. Sur la base de ce cadre, le GACVS a conclu que les études de la toxicité chez l'animal et chez l'homme tendaient à montrer que les concentrations d'éthylmercure dans le sang et dans le cerveau dues aux doses cumulatives de thiomersal présent dans les vaccins n'atteignaient pas un niveau toxique, ce qui rendait peu plausible du point de vue biologique un lien entre le thiomersal présent dans les vaccins et sa toxicité neurologique.

Sur la base des données actuelles, le GACVS considère qu'il n'est pas nécessaire d'effectuer des études supplémentaires sur l'innocuité du thiomersal dans les vaccins et que les données disponibles montrent de manière convaincante que son utilisation comme conservateur dans les vaccins inactivés est sans danger. Le GACVS estime que d'autres données suggérant le contraire ne devraient être prises en compte que sur la base d'études suivant les mêmes normes de haut niveau concernant l'inférence épidémiologique et causale, exigées pour la recherche scientifique. Le thiomersal permet à des millions de gens dans le monde de bénéficier de vaccins salvateurs et, à ce jour, aucune autre alternative plus sûre et aussi efficace n'a été trouvée pour de nombreux vaccins.

\section{Adjuvants à base d'aluminium}

Le GACVS a examiné 2 articles publiés avançant que l'aluminium contenu dans les vaccins est associé à des troubles du 
ANEXO F - PREÇOS MÁXIMOS DE MEDICAMENTOS POR PRINCÍPIO ATIVO PARA COMPRAS PÚBLICAS

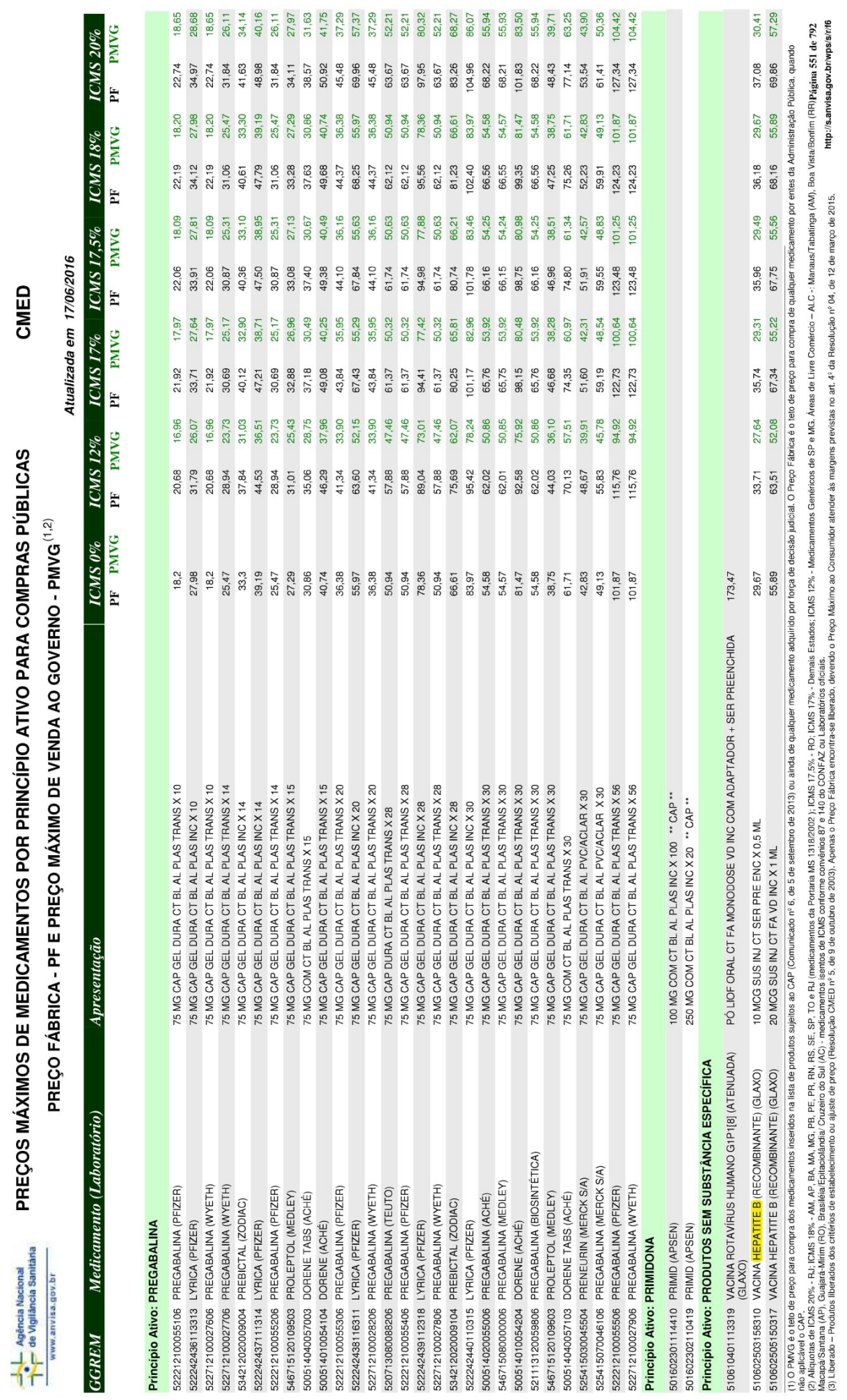




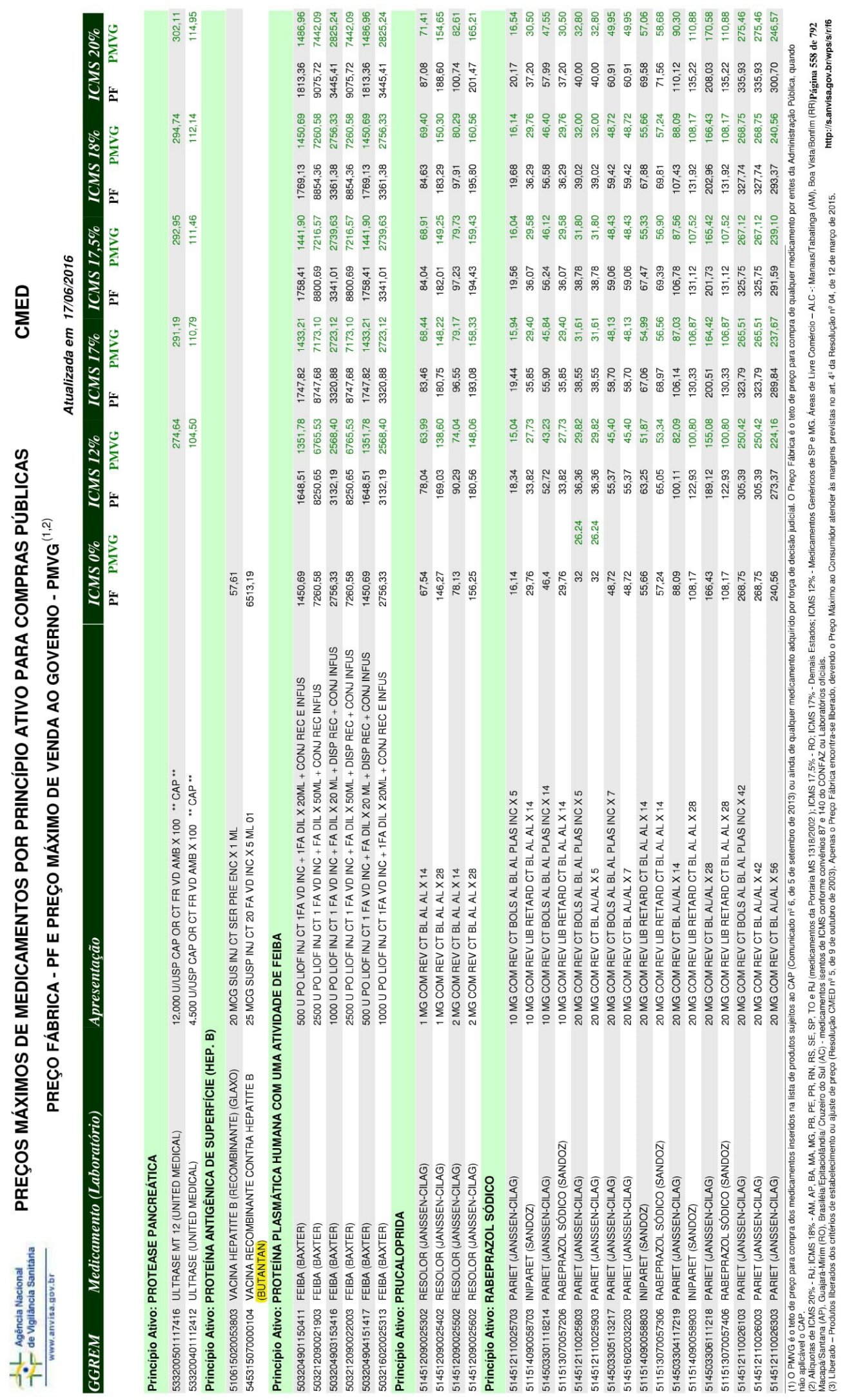

